OPEN ACCESS

Edited by:

Elizabeth Helen Aitken,

The University of Melbourne, Australia

Reviewed by:

Luana Ortolan,

Seattle Children's Research Institute,

United States

Lin Lin Caroline Chua,

Taylor's University, Malaysia

*Correspondence:

Julie M. Moore

juliemoore@ufl.edu

${ }^{t}$ This manuscript is dedicated to the memory of our dear friend and colleague

Specialty section: This article was submitted to Microbial Immunology, a section of the journal

Frontiers in Immunology

Received: 19 March 2021 Accepted: 17 September 2021 Published: 19 October 2021

Citation:

Sarr D, Oliveira $L J$, Russ BN, Owino SO, Middii JD, Mwalimu S,

Ambasa L, Almutairi F, Vulule J,

Rada B and Moore JM (2021) Myeloperoxidase and Other Markers of Neutrophil Activation Associate With Malaria and Malaria/HIV Coinfection in the Human Placenta.

Front. Immunol. 12:682668. doi: 10.3389/fimmu.2021.682668

\section{Myeloperoxidase and Other Markers of Neutrophil Activation Associate With Malaria and Malaria/HIV Coinfection in the Human Placenta}

\author{
Demba Sarr ${ }^{1}$, Lilian J. Oliveira ${ }^{2,3}$, Brittany N. Russ ${ }^{3}$, Simon O. Owino ${ }^{3,4,5,6}$, \\ Joab D. Middiii ${ }^{4,5,7}$, Stephen Mwalimu ${ }^{4,5,8}$, Linda Ambasa ${ }^{4,5,9}$, Faris Almutairi ${ }^{1,10}$, \\ John Vulule ${ }^{4 \dagger}$, Balázs Rada ${ }^{1}$ and Julie M. Moore ${ }^{3,4,5^{*}}$
}

${ }^{1}$ Department of Infectious Diseases, College of Veterinary Medicine, University of Georgia, Athens, GA, United States, ${ }^{2}$ Department of Pathology, College of Veterinary Medicine, University of Georgia, Athens, Georgia, United States, ${ }^{3}$ Department of Infectious Diseases and Immunology, College of Veterinary Medicine, University of Florida, Gainesville, FL, United States, ${ }^{4}$ Vector Biology and Control Research Centre, Kenya Medical Research Institute, Kisian, Kenya, ${ }^{5}$ University of Georgia/Kenya Medical Research Institute Placental Malaria Study, Siaya District Hospital, Siaya, Kenya, ${ }^{6}$ Faculty of Science, Department of Zoology, Maseno University, Maseno, Kenya, ${ }^{7}$ Kisumu Specialists Hospital Laboratory, Kisumu, Kenya, ${ }^{8}$ Animal and Human Health Program, International Livestock Research Institute, Nairobi, Kenya, ${ }^{9} \# 1$ Heartsaved Adult Family Care, Marysville, WA, United States, ${ }^{10}$ Department of Pharmaceutical and Biomedical Sciences, College of Pharmacy, University of Georgia, Athens, GA, United States

Introduction: Placental malaria (PM) is characterized by accumulation of inflammatory leukocytes in the placenta, leading to poor pregnancy outcomes. Understanding of the underlying mechanisms remains incomplete. Neutrophils respond to malaria parasites by phagocytosis, generation of oxidants, and externalization of Neutrophil Extracellular Traps (NETs). NETs drive inflammation in malaria but evidence of NETosis in PM has not been reported. Neutrophil activity in the placenta has not been directly investigated in the context of PM and PM/HIV-co-infection.

Methods: Using peripheral and placental plasma samples and placental tissue collected from Kenyan women at risk for malaria and HIV infections, we assessed granulocyte levels across all gravidities and markers of neutrophil activation, including NET formation, in primi- and secundigravid women, by ELISA, western blot, immunohistochemistry and immunofluorescence.

Results: Reduced peripheral blood granulocyte numbers are observed with PM and PM/HIV co-infection in association with increasing parasite density and placental leukocyte hemozoin accumulation. In contrast, placental granulocyte levels are unchanged across infection groups, resulting in enhanced placental: peripheral count ratios with PM. Within individuals, PM- women have reduced granulocyte counts in placental relative to peripheral blood; in contrast, PM stabilizes these relative counts, with HIV coinfection tending to elevate placental counts relative to the periphery. In placental blood, indicators of neutrophil activation, myeloperoxidase (MPO) and proteinase 3 (PRTN3), are significantly elevated with PM and, more profoundly, with $\mathrm{PM} / \mathrm{HIV}$ co-infection, in association with placental parasite density and hemozoin-bearing leukocyte accumulation. Another neutrophil marker, matrix 
metalloproteinase (MMP9), together with MPO and PRTN3, is elevated with self-reported fever. None of these factors, including the neutrophil chemoattractant, CXCL8, differs in relation to infant birth weight or gestational age. CXCL8 and MPO levels in the peripheral blood do not differ with infection status nor associate with birth outcomes. Indicators of NETosis in the placental plasma do not vary with infection, and while structures consistent with NETs are observed in placental tissue, the results do not support an association with PM.

Conclusions: Granulocyte levels are differentially regulated in the peripheral and placental blood in the presence and absence of PM. PM, both with and without pre-existing HIV infection, enhances neutrophil activation in the placenta. The impact of local neutrophil activation on placental function and maternal and fetal health remains unclear. Additional investigations exploring how neutrophil activation and NETosis participate in the pathogenesis of malaria in pregnant women are needed.

Keywords: neutrophils, pregnancy, NETs (neutrophil extracellular traps), placental malaria, myeloperoxidase, Plasmodium falciparum

\section{INTRODUCTION}

Malaria infection during pregnancy is a significant public health problem with substantial effects on the mother, her fetus, and the newborn child [reviewed by (1)]. Accumulation of parasites in the placenta is a common feature of Plasmodium falciparum infection in pregnant women, mediated by VAR2CSA, a parasite protein exported to the surface of infected red blood cells, which binds to chondroitin sulfate A on proteoglycans, including syndecan-1 (2), in the placenta. Paucigravid women (in the first or second pregnancy) are especially vulnerable and are more likely than multigravidae (three or more pregnancies) and nonpregnant women to develop severe malaria (1). The interplay between parasites and the placenta is associated with inflammation characterized by the recruitment, retention, and activation of innate immune cells including polymorphonuclear leukocytes (neutrophils) (3) and is known as placental malaria (PM) (4). PM is associated with adverse pregnancy outcomes such as maternal anemia, stillbirth, and low birth weight (LBW) due to intrauterine growth restriction, and is most severe in the first pregnancy (5). How neutrophils in particular may affect placental pathology and fetal growth in the context of malaria remains a mystery.

Previous studies addressing potential interactions between PM and HIV infection suggest that the latter impairs immunity against malaria (6). HIV-infected pregnant women have more frequent and higher density parasitemia than HIV-negative pregnant women (7-11). Importantly, malaria accelerates HIV disease progression and higher viral load among pregnant women. Fetal complications in PM and association between maternal HIV status and fetal outcome have also been addressed (11-17). A definitive role for neutrophils in pathogenesis of PM alone and co-infections with HIV has been rarely studied. In one study, the number of circulating pigmented (Hz-bearing) neutrophils negatively correlated with birth weight, suggesting that these cells may have a pathogenic role in PM and thus may serve as prognostic markers for malariaassociated low birth weight (18). Another study reported that circulating neutrophils were reduced in pregnant women with
P. falciparum malaria compared to negative controls (3). Others have found elevated neutrophil levels in placental relative to peripheral blood in malaria-infected women (19). Limited studies that performed direct measures have noted increased neutrophil levels by placental histopathology $(20,21)$. Consistent with this, cytokines and chemokines that can attract neutrophils, namely MIF, CXCL8/IL-8, and CCL3, are elevated in human PM (22-27).

Neutrophils are essential effector cells of the innate immune system. In humans, neutrophils are the most abundant type of white blood cell, accounting for $70 \%$ of all leukocytes in the blood of healthy adults (28). During pregnancy, the neutrophil count begins to increase in the second month and plateaus in the second or third trimester, a time at which the total number of white blood cells ranges from 9,000 to $15,000 \times 10^{6} / \mathrm{L}$ (29). These cells are classically considered to be short-lived and act as the first line of defense in innate immunity, ensuring tissue restitution following resolution of infection (30-32). Neutrophils can rapidly be recruited to sites of infection and tissue injury (33), where they generate reactive oxygen species (ROS) through the activity of NADPH oxidase, thereby initiating antibacterial/antiparasitic defense (34). Neutrophils clear infections by phagocytosis, generation of ROS, release of potent bactericidal enzymes by degranulation, and formation of neutrophil extracellular traps (NETs) (35).

As evidenced in malaria, however, neutrophils represent a doubleedged sword. These cells are activated and are capable of clearing malaria parasites by a variety of mechanisms (reviewed by (36), yet they are implicated in pathogenic mechanisms as well (37). Mice developing malaria-associated acute lung injury/acute respiratory distress syndrome (ALI/ARDS) had greater neutrophil accumulation in the lungs compared to mice that did not develop pulmonary complications (38). In these mice, targeting of neutrophils decreased the development of malaria-associated ALI/ARDS and significantly increased mouse survival (38), suggesting that neutrophils play a significant role in the pathogenesis of ALI/ARDS during experimental severe malaria and could be targeted to improve disease outcome.

Oxidative damage to tissues is also a key attribute of malaria pathogenesis that may be in part attributable to neutrophils. 
Retinopathy-positive cerebral malaria is associated with accumulation of neutrophils (39). Likewise, previous work with $P$. chabaudi and $P$. berghei ANKA infection in mice indicated that neutrophils were responsible for liver damage, cerebral complications, and ALI/ARDS (38, 40, 41). Uptake of hemozoin $(\mathrm{Hz})$-containing digestive vacuoles by neutrophils drives a rapid oxidative burst but suppresses subsequent neutrophil activity (42). Oxidative damage in PM has been reported in humans and in mouse models, but key drivers remain unclear (43-46).

NETs are generated by the extrusion of DNA strands into the extracellular milieu, where they can entrap invasive pathogens $(47,48)$. The most common method for NET detection in vitro is microscopic observation (49), with immunodetection of neutrophil-derived proteins such as myeloperoxidase (MPO) and proteinase 3 (PRTN3) $(50,51)$ colocalized with DNA (49). NETs in tissue samples have similarly been shown as extracellular DNA colocalized with neutrophil-derived proteins (49). NET remnants such as DNA and neutrophil-derived protein complexes (MPO-DNA; neutrophil elastase (NE)DNA) and citrullinated histones can be determined by ELISA in fluid samples $(50,51)$ or detected by flow cytometry $(52,53)$ as indicators of NETosis.

A role for NETosis in both protection and pathogenesis in malaria is emerging. P. falciparum-infected red blood cells reportedly stimulate human neutrophils to release NETs in vitro (38). The latest mechanistic investigations of NETs in malaria show that they are released by neutrophils exposed to malaria parasites and impede parasite spread thereby controlling infection (54). Furthermore, these studies provide evidence that NET release in malaria is independent of cell-cell contact and is mediated by macrophage migration inhibitory factor and peptidylarginine deiminase 4 (PAD4)-dependent histone citrullination (54). Interestingly, malaria parasite species have been shown to produce DNase that degrades NETs and the deficiency of this enzyme resulted in lower parasitemia in mice (55). Importantly, NETosis has been linked to severe malaria in human infection and in mouse models $(38,56-58)$. Using human samples and a mouse model for malaria, Knackstedt et al. demonstrated that hemeinduced NETs are essential for malaria pathogenesis, with granulopoiesis and endothelial cell activation as two mechanisms of NET-mediated inflammation of the vasculature (58).

The present study investigates granulocyte levels and neutrophil activity in the peripheral and placental blood and tissue of parturient Kenyan women exposed to malaria and HIV. Neutrophils and associated markers appear to be influenced by these infections and preliminary evidence of NETosis in the placenta blood is offered. These data show a potential implication of neutrophils in the pathogenesis of PM but further studies are required to characterize the mechanisms by which this occurs.

\section{MATERIAL AND METHODS}

\section{Ethics Statement}

The study supporting collection of samples used in this report was approved by the Kenya Medical Research Institute, the Centers for Disease Control and Prevention, and the
University of Georgia Institutional Review Boards. All study participants provided written informed consent before enrollment and procedures and instruments involving human subjects, sample collection and data analysis, processing, and testing were approved throughout the conduct of patient recruitment. All samples and data are anonymized.

\section{Study Participants and Sample Collection}

Participant recruitment and sample collection have been previously described $(11,59)$ (Matthias et al., manuscript in preparation). Briefly, the recruitment of 222 participants was performed at New Nyanza Provincial General Hospital, a public referral hospital, in Kisumu from November, 2002 to May, 2004. Subsequently, 825 participants were recruited at Siaya District Hospital, a public secondary health facility in Siaya until September, 2008. Women of all gravidities and uncomplicated vaginal deliveries were randomly recruited from patients admitted to the Delivery Ward of these hospitals. Only women with no health issues aside from malaria or HIV were eligible for full participation in the study. Maternal demographic and clinical information was collected and summarized, including whether or not participants self-reported fever within the two weeks prior to delivery. Infant gestational age was estimated using the modified Dubowitz score, and birth weight in grams was measured within eight hours after delivery. Maternal placental (intervillous) blood (IVB) was collected by the prick method within five minutes of placental expulsion (60). Peripheral blood was collected by venipuncture of the cubital vein within 12 hours post-partum. Platelet-free plasma was prepared as described (59) and stored continuously at $-80^{\circ} \mathrm{C}$, avoiding multiple cycles of freeze-thaw. Complete blood count (CBC) of both peripheral blood and IVB to estimate total white blood cell (WBC) and granulocyte counts was performed simultaneously with a Beckman Coulter AcT diff2 (Beckman Coulter Corporation, Miami, FL) within eight hours of blood collection. Although the majority of granulocytes detected by $\mathrm{CBC}$ are expected to be neutrophils, differential analysis for granulocytes was not available; thus, granulocyte levels are reported for this study. Full thickness placental tissue sections were collected from three unique regions of the placental disk, and fixed in Streck Tissue Fixative (Streck Inc., Omaha, NE). Five-micron sections were stained with hematoxylin and eosin for histopathological examination or left unstained for immunohistochemical analysis. From the same placental regions, $125 \mathrm{~mm}^{3}$ sections of villus tissue underlying the placental basal plate were collected and flash frozen in liquid nitrogen for future molecular analysis and with Tissue-Tek OCT compound (Sakura Finetek USA, Inc., Torrance, CA) for immunofluorescence assessments and stored continuously at $\leq-80^{\circ} \mathrm{C}$ until use.

Parasitemia was assessed on thick and thin smears of peripheral and placental blood and estimation of thick smear parasite density assumed $8,000 \mathrm{WBCs}$ per $\mu \mathrm{L}$ of blood for both peripheral and placental blood. Percentage of leukocytes in the maternal placental vascular space bearing $\mathrm{Hz}$ was calculated from these thick smears. HIV serostatus was determined by rapid tests as previously described $(11,59)$. 


\section{Study Designs}

Among the 1047 women recruited into the study, samples and data from a subset of 379 women are included in the work described here. Sample selection and use are summarized in Figure $\mathbf{1}$ and Supplemental Figure 1, and patient characteristics are summarized in Table 1. All malaria infections are attributable to P. falciparum; a single participant was diagnosed with a $P$. falciparum $/ P$. malariae mixed infection. Paired peripheral and placental data from Complete Blood Count were available from 224 women (79 primigravidae, 54 secundigravidae and 91 multigravidae, representing four infection groups (uninfected, malaria only (PM+HIV-), HIV only (PM-HIV + ), and co-infected $(\mathrm{PM}+\mathrm{HIV}+))$. Gravidity differs significantly across the infection groups providing $\mathrm{CBC}$ data $(P=0.0093$ by Kruskal-Wallis test with post-hoc group-wise comparisons by Dunn's multiple comparisons test; median, interquartile range (IQR): PM-HIV-, 2, 1 - 3; PM+HIV-, 1, 1 - 2; PM-HIV+, 3, 2 - 4; PM+HIV+, 2, 1 - 3). Subsequent analyses focused on primigravid and secundigravid (paucigravid) women who experience the most significant outcomes with malaria and HIV infections in this setting $(10,61)$ (Matthias et al., manuscript in preparation).

Pilot data to detect markers of neutrophil activation and NETosis (cell-free DNA, DNA-human neutrophil elastase (NE) complexes, histones) in placental plasma were generated using HIV seronegative primigravid placental plasma (Figure 1), selected on the basis of placental histopathological status (uninfected, and infected: acute, chronic, chronic inflammatory). Acute infection is defined as the presence of infected red blood cells (iRBC), white blood cell (WBC) count by $\mathrm{CBC}<13,000 / \mathrm{uL}$, and hemozoin scores [as described in (Avery et al., 2012)] $\leq 1$ in WBCs and in fibrin. Chronic infection is defined as presence of $\mathrm{iRBC}$, WBC count $<13,000 / \mathrm{uL}$, and hemozoin scores $\geq 2$ in WBCs and in fibrin. Chronic inflammatory infection is defined as presence of iRBC, WBC count $>13,000 / \mathrm{uL}$, and hemozoin scores $\geq 2$ in WBCs and in fibrin. Uninfected samples were confirmed parasite PCR negative and lacked iRBCs in histological sections. Subsequent ELISA data were generated from paucigravid women (Figure 1), representing malaria and HIV positive and negative women, with balanced selection of primigravid and secundigravid women within each infection group (PM-HIV-, PM+HIV-, PM$\mathrm{HIV}+, \mathrm{PM}+\mathrm{HIV}+$ ), and with matched selection across groups of infant birth weights, in both cases to the extent that sample availability allowed. Frozen placental tissues for immunofluorescence were selected to represent each infection group from among samples with MPO data, based on sample availability (Figure 1). Immunohistochemistry and western blot experiments utilized paucigravid samples (Figure 1), representing the four infection groups, with matched selection for granulocyte count (by $\mathrm{CBC}$ ) ranges across each group.

\section{ELISA}

Levels of myeloperoxidase (MPO), proteinase 3 (PRTN3), matrix metalloproteinase (MMP9), and CXCL8 were quantified in peripheral and placental blood using a commercial ELISA kit

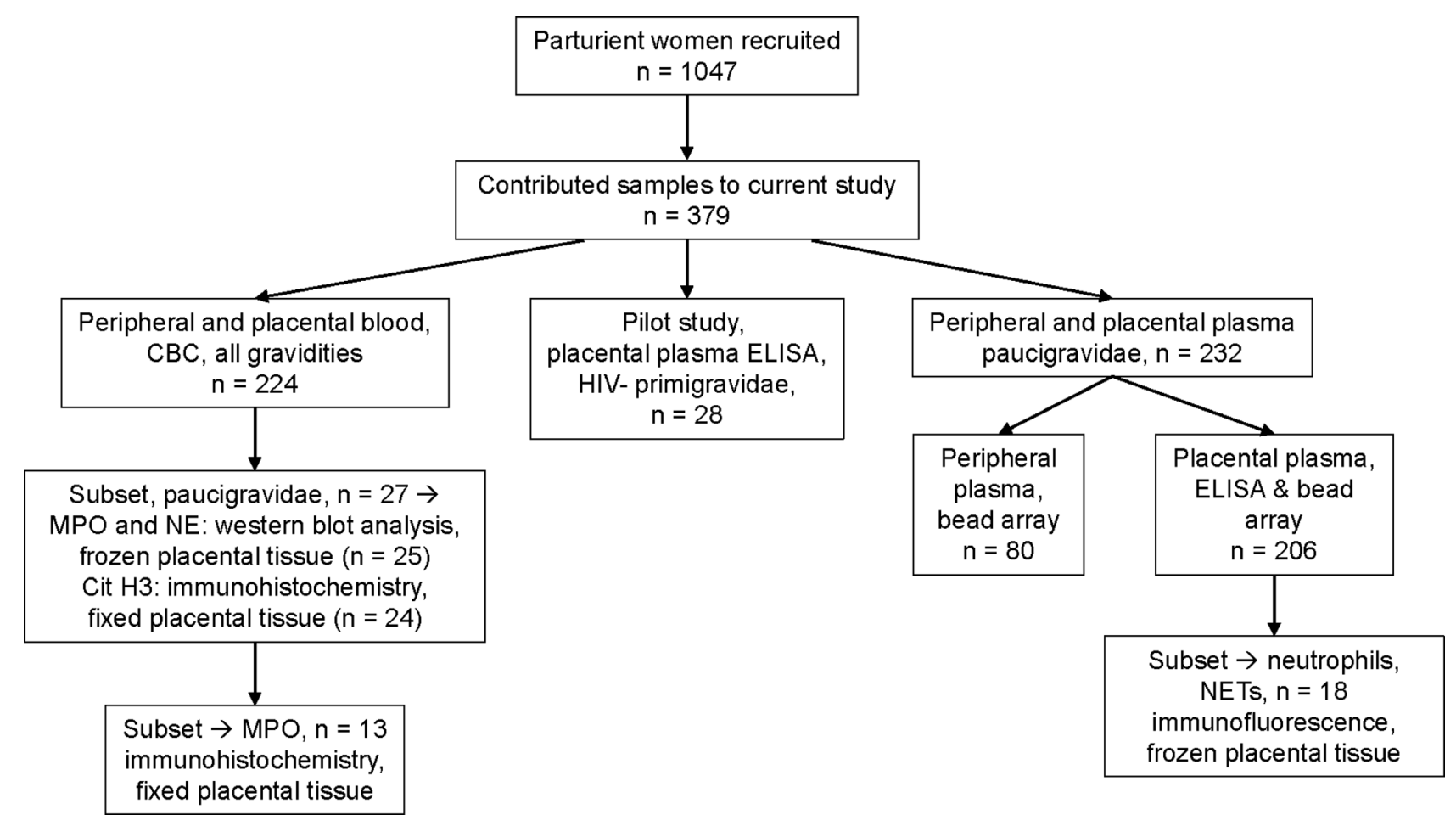

FIGURE 1 | Diagram of sample collection and testing. Shown are the number of patients recruited in a large cohort of parturient women in western Kenya, and samples contributed and tested in this study. Details of sample selection criteria are described in Materials and methods. Overlap of sample assessment on a per patient basis is depicted in Supplemental Figure $\mathbf{1}$ 
TABLE 1 | Descriptive characteristics of study population stratified by gravidity.

\begin{tabular}{|c|c|c|c|c|}
\hline Characteristics & All Women $(n=379)$ & Paucigravid $(n=288)$ & Multigravid $^{\mathrm{a}}$ ( $\mathrm{n}=91$ ) & $P$-value ${ }^{\text {b }}$ \\
\hline \multicolumn{5}{|l|}{ Maternal Sociodemographic } \\
\hline Gravidity & $1(1-11)$ & $1(1-2)$ & $4(3-11)$ & - \\
\hline Primigravid (\%) & $192(50.6)$ & $192(66.7)$ & - & - \\
\hline Age (years) & $21(13-39)$ & $19(13-32)$ & $26(20-39)$ & $<0.0001$ \\
\hline Married (\%) & $258(68.1)$ & $171(59.4)$ & 87 (95.6) & $<0.0001$ \\
\hline Luo ethnicity (\%) & $\begin{array}{c}348(91.8) \\
(\mathrm{n}=377)\end{array}$ & $\begin{array}{c}259(90.5) \\
(n=286)\end{array}$ & $89(97.8)$ & 0.0230 \\
\hline Siaya $^{\mathrm{C}}$ residence $(\%)$ & $342(90.2)$ & $251(87.1)$ & $91(100)$ & $<0.0001$ \\
\hline \multicolumn{5}{|l|}{ Laboratory } \\
\hline Fever $^{\mathrm{d}}$ at admission (\%) & $\begin{array}{c}4(3.3) \\
(n=123)\end{array}$ & $\begin{array}{l}3(3.1) \\
(n=97)\end{array}$ & $\begin{array}{l}1(3.8) \\
(n=26)\end{array}$ & 1 \\
\hline HIV $^{e}$ seropositive* $(\%)$ & $103(27.2)$ & $75(26)$ & $28(30.8)$ & 0.4177 \\
\hline Malaria smear positive* $(\%)$ & $131(34.6)$ & $113(39.2)$ & $18(19.8)$ & 0.0006 \\
\hline Parasite density $/ \mu \mathrm{L}^{\mathrm{f}}$ (range; interquartile range) & $\begin{array}{c}\text { 4,976 (40-226,208; } \\
618-25,345)(n=131)\end{array}$ & $\begin{array}{c}5,208(40-226,208 \\
958-31,188)(n=113)\end{array}$ & $\begin{array}{c}2,433(83-119,107 \\
479-7,521)(n=18)\end{array}$ & 0.0752 \\
\hline Peripheral hemoglobin ${ }^{g}$ (g/dL) & $\begin{array}{c}11.3(5.30-20.4) \\
(n=319)\end{array}$ & $\begin{array}{c}11.3(5.30-20.2) \\
(n=228)\end{array}$ & $\begin{array}{c}11.4(5.80-20.4) \\
(n=91)\end{array}$ & 0.5433 \\
\hline Placental hemozoin load ${ }^{\mathrm{h}}$ & $\begin{array}{c}3.5(0.3-82) \\
(n=127)\end{array}$ & $\begin{array}{c}3.7(0.3-82) \\
(n=108)\end{array}$ & $\begin{array}{c}1.6(0.6-54) \\
(n=19)\end{array}$ & 0.1820 \\
\hline \multicolumn{5}{|l|}{ Newborn } \\
\hline Birth weight $(\mathrm{g})$ & $3,200(2,000-4,500)$ & $3,000(2,000-4,400)$ & $3,400(2,600-4,500)$ & $<0.0001$ \\
\hline Low birth weight ( $\leq 2500 \mathrm{~g})(\%)$ & $61(16.1)$ & $61(21.2)$ & $0(0)$ & $<0.0001$ \\
\hline Gestational age (weeks) & $\begin{array}{c}38(34-42) \\
(n=376)\end{array}$ & $\begin{array}{c}38(34-40) \\
(n=285)\end{array}$ & $38(35-42)$ & 0.0116 \\
\hline Preterm birth (<37 weeks) (\%) & $\begin{array}{c}56(14.9) \\
(n=376)\end{array}$ & $\begin{array}{c}49(17.2) \\
(n=285)\end{array}$ & $7(7.7)$ & 0.0277 \\
\hline Male infant (\%) & $193(50.9)$ & $150(52.1)$ & $43(47.2)$ & 0.4709 \\
\hline \multicolumn{5}{|l|}{ Self-reported history } \\
\hline Fever, past two weeksi (\%) & 77 (20.3) & $63(21.9)$ & $14(15.4)$ & 0.2315 \\
\hline
\end{tabular}

Data are shown as number (percent) or median (range) unless otherwise noted. Sample sizes are shown where missing data reduce group numbers for specific parameters or only a subset of the group have values $>0$.

${ }^{a}$ Multigravidae contribute complete blood count data only;

${ }^{b}$ Comparison of paucigravidae with multigravidae by two-tailed Fisher's exact test (proportions), Mann Whitney test (continuous data) or Welch's t test (log transformed continuous data). cremainder were recruited in Kisumu:

${ }^{d}$ defined as $>37.6^{\circ} \mathrm{C}$.

${ }^{e} \mathrm{HIV}$, human immunodeficiency virus;

${ }^{f}$ parasitemia measured in placental blood, analysis done on log-transformed data;

${ }^{g}$ by complete blood count.

${ }^{h}$ percent white blood cells observed on placental blood thick smear with engulfed hemozoin;

iself-reported fever or malaria in the last two weeks;

*factors used to guide sample selection.

(R\&D Systems, DuoSet, Minneapolis, MN) or bead arrays (R\&D Systems) following manufacturer instructions and as previously described $(62,63)$. The experimental lower limits of detection for MPO were $125 \mathrm{pg} / \mathrm{ml}$ (ELISA) and $130 \mathrm{pg} / \mathrm{mL}$ (bead array), 125 $\mathrm{pg} / \mathrm{mL}$ for MMP9, $10 \mathrm{pg} / \mathrm{mL}$ for PRTN3 and $3.9 \mathrm{pg} / \mathrm{mL}$ for CXCL8. Citrullinated histone $\mathrm{H} 3$ was measured using a kit from Cayman Chemical (Ann Arbor, MI), with a lower limit of detection at $0.1 \mathrm{ng} / \mathrm{mL}$. Levels of NE-DNA complexes were assessed using an in-house protocol established to detect NET formation (64). In this assay, rabbit anti-NE $(1: 2,000$, Calbiochem, San Diego, CA) was used as capture antibody and horseradish peroxidase-conjugated anti-DNA antibody (1:500, Roche, Indianapolis, IN) as detection antibody. Cell-free double stranded DNA was detected using the Quant-iT ${ }^{\mathrm{TM}}$ PicoGreen ${ }^{\mathrm{TM}}$ dsDNA Assay Kit (ThermoFisher Scientific, Grand Island, NY, USA) according to the manufacturer's instructions. DNA concentrations were quantitated using a known DNA standard with a lower limit of detection of $5 \mathrm{ng} / \mathrm{mL}$ as previously described (65). Total histone H3 levels were detected using a commercial kit (Active Motif, Carlsbad, CA) according to manufacturer instructions; the lower limit of detection was $150 \mathrm{ng} / \mathrm{mL}$.

\section{Immunohistochemistry and Immunofluorescence}

Unstained $5 \mu \mathrm{m}$ placental tissue sections were dewaxed for 15 minutes at $65^{\circ} \mathrm{C}$ followed by two incubations in xylene $(2 \times 5$ minutes). Sections were then rehydrated in alcohol and antigenretrieved with Sodium Citrate Buffer as previously described (66). Sections were then brought to room temperature and exposed to endogenous peroxidase activity block (DAKO, Cat\#S2023) for 15 minutes. After washing with 1X TBST, sections were incubated with $10 \%$ Goat Serum for 10 minutes and incubated with the primary antibody (1/500 for MPO or $1 /$ 500 for citH3 in $1 \%$ Goat Serum) overnight at $4^{\circ} \mathrm{C}$. The next day, samples were washed with $1 \mathrm{X}$ TBST $(3 \times 5$ minutes) and incubated with polymer HRP anti-rabbit IgG for 30 minutes at RT. After three washes in $1 \mathrm{X}$ TBST, sections were exposed to $\mathrm{DAB}$ for 5 minutes, washed with distilled water, counterstained 
with hematoxylin (Cat\#H3401-500, Vector Laboratories), dehydrated, and mounted with acrytol mounting medium (Cat\#13518, Electron Microscopy Sciences, Hatfield, USA).

Immunofluorescent analysis was performed on $5 \mu \mathrm{m}$ cryosections of OCT-preserved placental tissue. The sections were fixed in ice-cold acetone for 10 minutes and air dried for 1 hour. Following a rehydration step with $0.05 \mathrm{mM}$ Tris-buffered saline (TBS; pH 7.5), sections were incubated with Protein Block, Serum-Free solution from Agilent DAKO (X0909, Santa Clara, CA, USA) for 1 hour. Rabbit anti-human MPO was purchased from Agilent DAKO (A039829-2, Santa Clara, CA, USA) and rabbit -anti-NE was purchased from Millipore-Sigma (481001, Burlington, MA, USA). Antibodies were pre-labeled using the Zenon Alexa Fluor 488 rabbit IgG1 labeling kit for anti-human MPO and Zenon Alexa Fluor 594 rabbit IgG1 labeling kit for anti-NE from Thermo Fisher Scientific (Waltham, MA USA). The labeled antibodies were diluted in Antibody Diluent reagent from Agilent DAKO (X0909, Santa Clara, CA, USA) at 1:100 and the sections incubated overnight a $4^{\circ} \mathrm{C}$. Negative controls were labelled with an irrelevant prelabeled isotype control at the same concentration and same labeling as the primary antibody. The sections were then washed three times in TBS and labeled with Hoescht 33342 reagent $(2.3 \mu \mathrm{g} / \mathrm{ml})$ for 15 minutes. The slides were washed again, and cover slips were mounted using Prolong Antifade mounting medium (Thermo Fisher Scientific, Waltham, MA USA).

Slides were examined using a Leica DM2500 LED microscope with filters 02 (DAPI filter), 03 (FITC filter) and 15 (rhodamine filter) at $20 \mathrm{X}$ magnification. Digital images were acquired using Leica LASX software and a high-resolution Leica DMC6200 digital camera. Five random fields within each villi section were captured for morphometric analysis within a $197.7 \mathrm{~mm}^{2}$ field of view (FOV). A total cell number was generated and analyzed for each sample based on the sum of the average number of cells per FOV in each sample.

For image analysis of immunohistochemistry samples, several random FOV were acquired in RBG format and exported as tag image format ( ${ }^{*}$ tif) with the respective metadata. Using QuPath v0.2.3-m4 software (67), the digital images were preprocessed using the built-in visual stain editor to estimate and adjust stain vectors to improve staining quality. The round cells in the intervillous spaces were manually annotated based on hematoxylin filter to warrant the selection of all nucleated cells in the analyzed FOV. The intensity of MPO staining was measured as optical density (OD) and classified by the module "positive cell detection" using adjusted pixel size $(0.1465 \mu \mathrm{M})$ to match the image resolution and automatic thresholds. The cell detection measurements were compiled. The number of positive cells and the intensity of DAB staining $\left(\right.$ per $\mathrm{mm}^{2}$ ) were used in the statistical analysis. All analyzed images were blindly evaluated by an observer for quality control purposes prior to data export. Due to the variability of preservation of intervillous blood among the samples, the minimum for evaluation was three FOV or at least 100 intervillous round cells.

Analysis of immunofluorescence samples was also performed using QuPath v0.2.3-m4 software (67). Images of three fluorescence channels (green, red and blue) were overlaid. The positive cells for either MPO or NE or dually positive cells were manually annotated. The annotated cells were always associated with blue stained nuclei (DNA material). The fluorescence intensity of MPO staining was measured in the green channel and intensity of NE staining was measured in the red channel using the "Analysis" and "Calculate features" with automatic thresholds. Additional overlays of negative controls were exported, and random areas were analyzed to set a threshold of nonspecific fluorescence by average of intensity of fluorescence in these areas in the green and red channels. An annotated cell was considered positive when the fluorescence intensity was higher than the average fluorescence intensity in either or both of the green and red channels in the negative controls. NETs were identified as dual positive for MPO and NE, associated with DNA staining, and with a size higher than $102 \mu \mathrm{M}^{2}$ as reported (68). All analyzed images were blindly evaluated by an observer for quality control purposes prior to data export.

\section{Western Blotting}

Placental villous tissue (30 mg frozen weight) was homogenized in RIPA buffer supplemented with proteinase inhibitor cocktail. Samples were homogenized with Tissue Lyser (Qiagen, Valencia, USA) and centrifuged at $10,000 \mathrm{~g}$ for 15 minutes. Protein concentrations were determined by bicinchoninic acid (BCA) method (Thermo Scientific, Rockford, USA) with bovine serum albumin (BSA) as a standard. Equal individual protein samples were prepared and stored at $-80^{\circ} \mathrm{C}$ until use. Proteins $(30 \mu \mathrm{g} /$ sample) were separated by SDS-PAGE, blotted onto nitrocellulose membranes (Biorad, Hercules, USA) and probed with monoclonal or polyclonal rabbit antibodies specific for MPO (Agilent Technology, Santa Clara, USA), NE (Abcam, Cambridge, USA), citrullinated histone H3 (Abcam), and Hsp 90 (Cell Signaling Technologies) (as a loading control). Overnight incubation with primary antibody at $4^{\circ} \mathrm{C}$ was followed by one-hour incubation with anti-rabbit horseradish peroxidase secondary conjugates (Vector Laboratories). Proteins were detected using an enhanced chemiluminescence reagent (Pierce, Rockford, IL, USA). ChemiDoc Touch Imaging System with Image Lab Touch Software (BioRad) was used for image acquisition and densitometry analysis. Densitometry data are presented as ratio of target protein to Hsp90.

\section{Statistical Analysis}

Graph Pad Prism 9.1 software was used for all graphical data presentation and statistical analysis. Data are presented as scatter plot (correlation analysis and categorical analysis, with median line). Details for statistical analysis are indicated in the text or in figure legends as appropriate. Parasite density and percent $\mathrm{Hz}$ bearing WBCs were log transformed prior to analyses. Binary analysis of non-normally distributed data of matched samples utilized the Wilcoxon matched-pairs signed rank test; unpaired analyses utilized the Mann-Whitney test. Correlation analysis was performed using the Spearman's correlation test. Multiple group comparisons were performed with Kruskal-Wallis test with post-hoc group-wise comparisons by Dunn's multiple 
comparisons test. Two-tailed Fisher's exact test was used to compare proportions. Statistical significance was set at $P<0.05$.

\section{RESULTS}

\section{Granulocyte Counts Are Differentially Impacted by Malaria and HIV Infection in the Peripheral and Placental Blood}

To determine the extent to which granulocyte levels are influenced by PM, and how pre-existing HIV infection may modify this response, granulocyte counts derived from $\mathrm{CBC}$ analysis of peripheral and placental blood from women of all gravidities were assessed. Counts do not vary with gravidity in peripheral (median, IQR: paucigravid, $10.0(6.90-13.7) \times 10^{3} / \mu \mathrm{L}$; multigravid, $9.10(7.30-11.5) \times 10^{3} / \mu \mathrm{L} ; P=0.6543$, Mann Whitney test) or placental blood (paucigravid, 7.80 (5.70 11.9) $\mathrm{x} 10^{3} / \mu \mathrm{L}$; multigravid, 7.80 (5.70 - 10.4); $\left.P=0.4889\right)$. Compared with control PM-HIV- women, peripheral granulocyte counts are reduced in $\mathrm{PM}+\mathrm{HIV}$ - and $\mathrm{PM}+\mathrm{HIV}+$ women (Figure 2A). The lower levels in the latter are strongly attributable to HIV infection, as levels between the two HIV+ groups are not significantly different $(P=0.5044)$. In contrast to peripheral blood, no differences in neutrophil counts in the placenta are evident (Figure 2B). Interestingly, the ratio of placental to peripheral blood granulocyte counts is enhanced by PM in both HIV- and HIV+ women (Figure 2C). Pairwise comparison of peripheral to placental granulocyte counts among individuals within the infection groups shows that while placental granulocyte levels are reduced relative to the periphery in uninfected and HIV seronegative women, this difference is lost with PM, with a tendency toward a reversed pattern in co-infected women (Figure 2D and Supplemental Table 1). Additionally, with the exception of PM+HIV+ women, in whom total WBC counts are strongly elevated in placental relative to peripheral blood, relative patterns of granulocyte levels between the peripheral and placental blood vary independently of total WBC counts (Supplemental Table 1 and Supplemental Figure 2A). In terms of proportion of total WBCs, granulocytes are universally substantially reduced in the placenta relative to the peripheral blood (Supplemental Figure 2B and Supplemental Table 1). However, whereas granulocyte percentages in the peripheral blood (Supplemental Figure 2C) follow the same trends observed with granulocyte counts (Figure 2A), placental granulocyte percentages reveal a distinct pattern of reduction in $\mathrm{HIV}+\mathrm{PM}+$ women (Supplemental Figure 2D) that is not observed in placental granulocyte counts (Figure 2B).

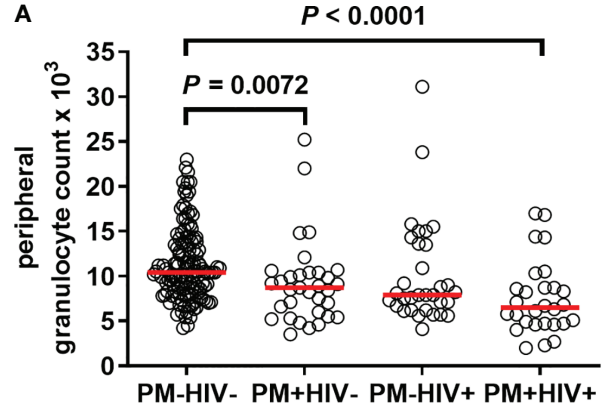

C

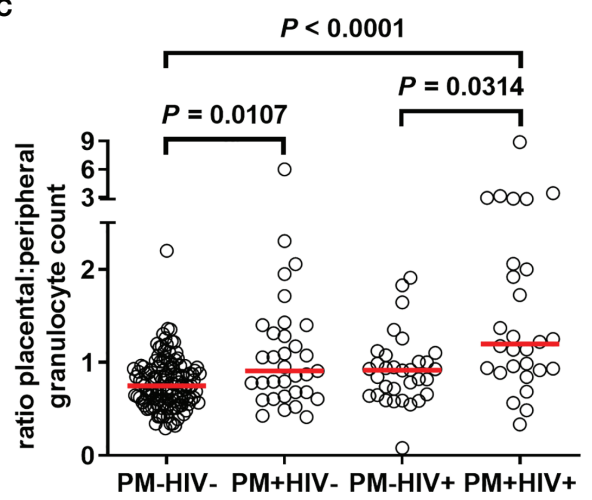

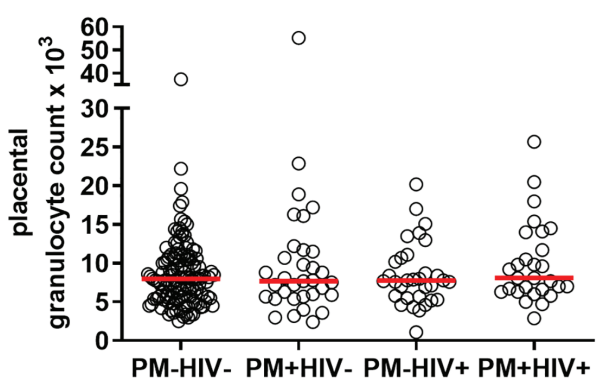

D

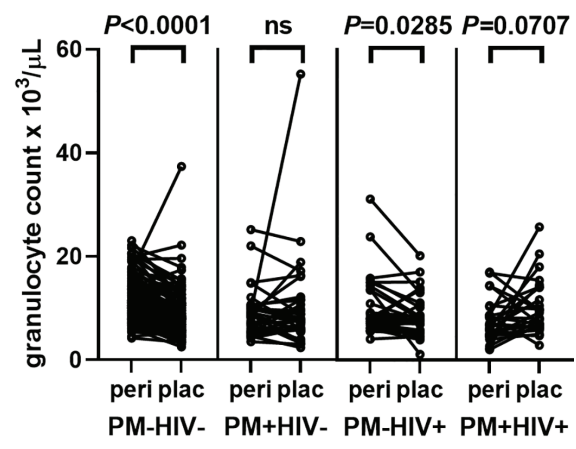

FIGURE 2 | Placental malaria and HIV infections differentially alter granulocyte levels in peripheral and placental blood. Peripheral and placental blood were subjected to complete blood count. Granulocyte numbers in (A) peripheral and (B) placental blood are shown. (C) Depicts the ratio of placental to peripheral blood granulocyte numbers, HIV-/PM-, $n=131$; HIV-/PM+, $n=33$; HIV+/PM-, $n=32 ; H I V+/ P M+, ~ n=28$. (A-C) Statistics by Kruskal-Wallis test with post-hoc group-wise comparisons by Dunn's multiple comparisons test. (D), pairwise comparisons by Wilcoxon matched-pairs signed rank test. PM-=placental malaria negative; PM+=placental malaria positive; HIV-=human immunodeficiency virus seronegative; HIV+=human immunodeficiency virus seropositive. 


\section{Granulocyte Counts Correlate With Indicators of PM Severity but Not Birth Outcomes}

PM often manifests as a chronic maternal inflammatory response dominated by accumulation of monocytes $(5,20,26$, 69). To assess the extent to which granulocyte counts might be influenced by severity of PM, correlation analysis of counts among $\mathrm{PM}+$ women (combined HIV- and HIV+) were performed with parasite density and the percentage of WBCs bearing $\mathrm{Hz}$ in the placental blood space, which is taken as an indicator of chronicity of placental infection. The placental granulocyte count is unrelated to placental parasite density (Figure 3A) but positively correlates with $\mathrm{Hz}$-bearing WBCs (Figure 3C). In contrast, the peripheral granulocyte count is inversely related to peripheral parasite density (Figure 3B) and Hz-bearing WBCs in the placenta (Figure 3D).

While granulocyte levels appear to be influenced by the intensity of the PM infection, no relationship with infant birth weight or gestational age is evident (Supplemental Table 2) nor do counts vary as a function of maternal self-reported fever (data not shown).

\section{Placental Blood MPO Increases With Placental Inflammation}

Based upon parameters including presence of parasites, inflammatory cell infiltration, and presence of $\mathrm{Hz}, \mathrm{PM}$ has been variously categorized in histopathological examination in attempts to summarize severity and longevity of PM and associated birth outcomes (70-73). As a first step toward probing functional attributes of neutrophils in PM, a pilot study was conducted to measure levels of MPO in placental plasma from HIV-seronegative primigravidae whose placentae were histologically categorized into four groups (uninfected, acute, chronic, and chronic, inflammatory infection). MPO is released upon activation of neutrophils in the blood and tissues into both the phagolysosomal compartment and the extracellular environment, as well as in NETs $(74,75)$. Relative to uninfected samples, placental plasma from tissues with evidence of chronic, inflammatory infection shows significantly elevated MPO levels (Figure 4A). Correspondingly, this group tends toward lower infant birth weights relative to uninfected women (Figure 4B). Placental MPO levels correlate positively with percent of $\mathrm{Hz}$ bearing WBCs in the placenta (Figure 4C). MPO levels are
A

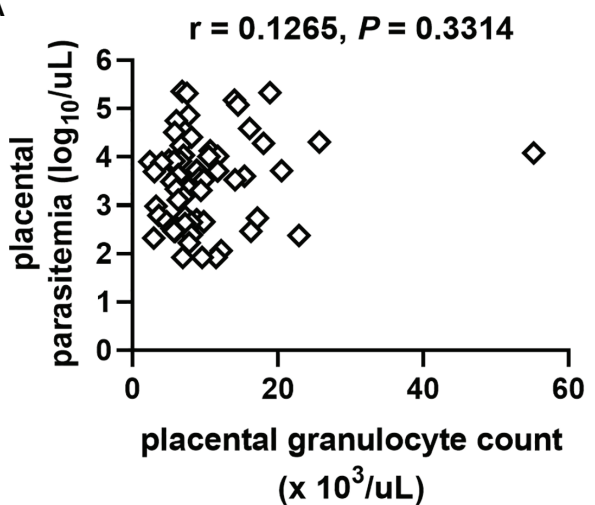

C

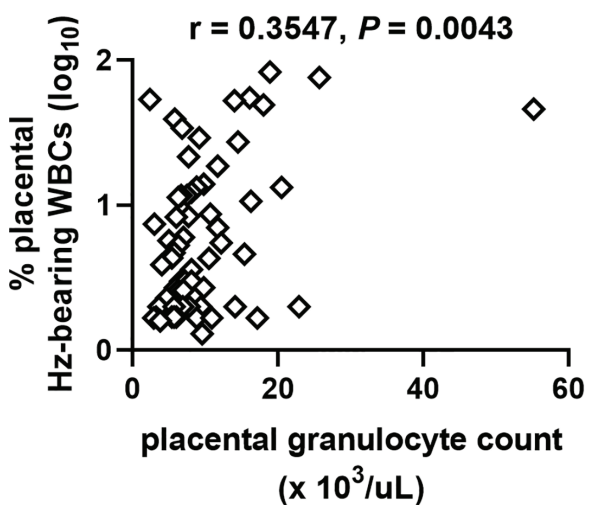

B

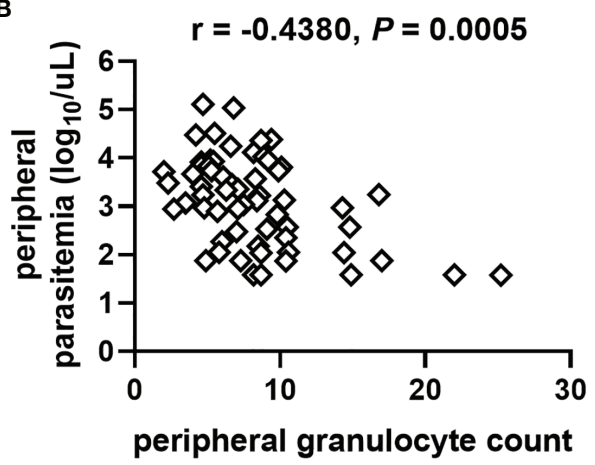

(x $\left.10^{3} / \mathrm{uL}\right)$

D

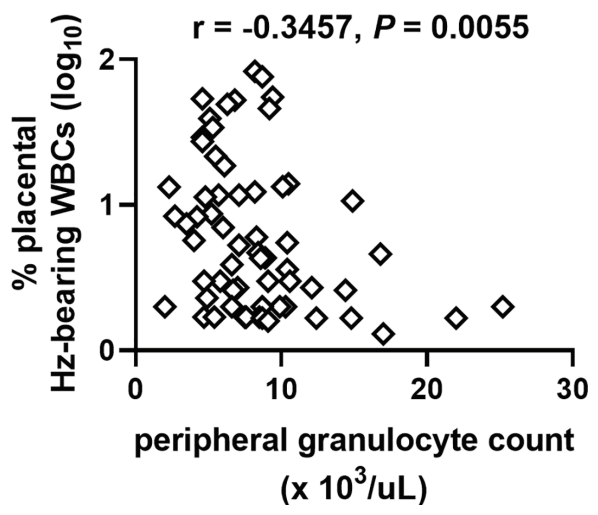

FIGURE 3 | Relationships of granulocyte numbers with measures of placental malaria vary as a function of blood source. Placental granulocyte counts measured by complete blood count in women with PM are unrelated to (A) placental parasite density but positively correlate with (C) the level of Hz-bearing WBCs in the placental intervillous space. Peripheral granulocyte counts negatively correlate with (B) peripheral parasite density and (D) level of Hz-bearing WBCs in the placental intervillous space. Both infection measures are log transformed. Results of Spearman's correlation analysis are shown. (A, B) $n=61 ;(\mathbf{C}, \mathbf{D}) n=63$. 
elevated with self-reported fever in these women and tend toward higher levels in those delivering low birth weight infants (Figure 4D). Overall, these data indicate that high MPO concentrations are associated with PM, especially chronic, inflammatory infection, and relevant clinical outcomes.

\section{Malaria and HIV Infection Impact Placental but Not Peripheral Levels of Soluble Markers of Neutrophil Activation}

Building upon these initial observations, a larger analysis was undertaken to identify the extent to which malaria and $\mathrm{PM} / \mathrm{HIV}$ co-infections in pregnant women impact indicators of neutrophil function. In addition to MPO, key markers of activated neutrophils, MMP9, and PRTN3, and a key neutrophil chemoattractant, CXCL8, were measured in peripheral and placental plasma of paucigravid women. In peripheral blood, MPO and CXCL8 levels are not impacted by $\mathrm{PM}$, regardless of HIV infection status (Figures 5A, B). Additionally, peripheral MPO and CXCL8 levels are unrelated to infant birth weight and gestational age at birth (Supplemental Figures 3E, F). In contrast, placental blood levels of MPO are significantly elevated with PM and PM/HIV co-infection relative to uninfected and HIV+ women, respectively (Figure 6A), and in mothers who reported recent fever (Figure 6B). CXCL8 levels in $\mathrm{PM}+\mathrm{HIV}+$ women are elevated relative to levels in uninfected women (Figure 6C), and tend toward a weak enhancement with reported fever (Figure 6D). While MMP9 levels remain unchanged with infection (Figure 6E), levels are enhanced with reported fever (Figure 6F). Finally, like MPO, PRTN3 levels are enhanced by PM in both HIV- and HIV+ women (Figure 6G), and are increased with recent fever (Figure 6H). Despite associations with PM, none of the measured markers differ as a function of birth weight or gestational age (Supplemental Figure 3). Placental levels of all of these factors significantly positively correlate with each other (Table 2 ), and with the exception of CXCL8, all positively correlate with placental parasite density (Figures 7A-D), and percent Hz-bearing WBCs in the placenta (Figures 7E-H). However, contrary to expectation, none of these factors correlate with granulocyte counts or percentages (data not shown).

\section{Placental MPO Detection by Immunohistochemistry and Western Blot}

To further characterize MPO expression in the placenta, tissue sections from a subgroup of patients were probed using
A

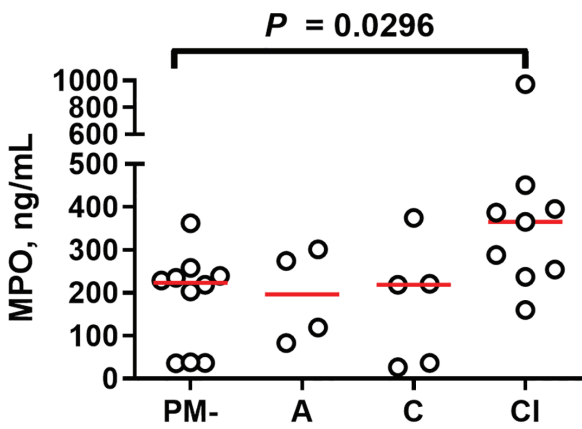

C

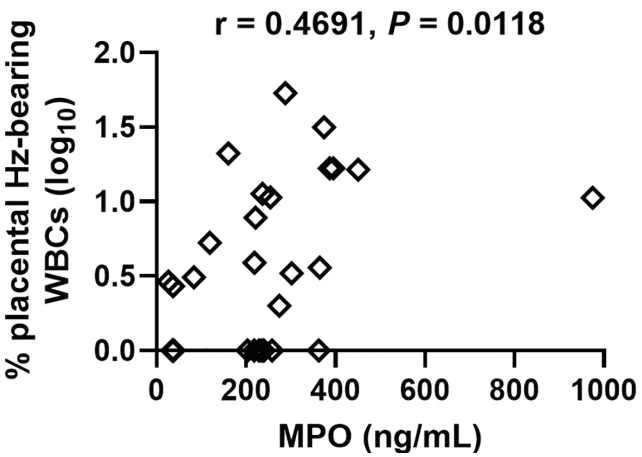

B

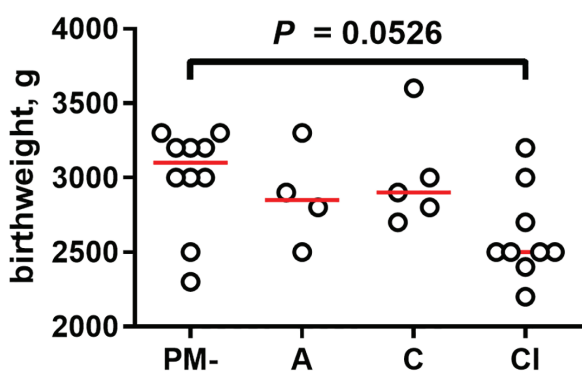

D

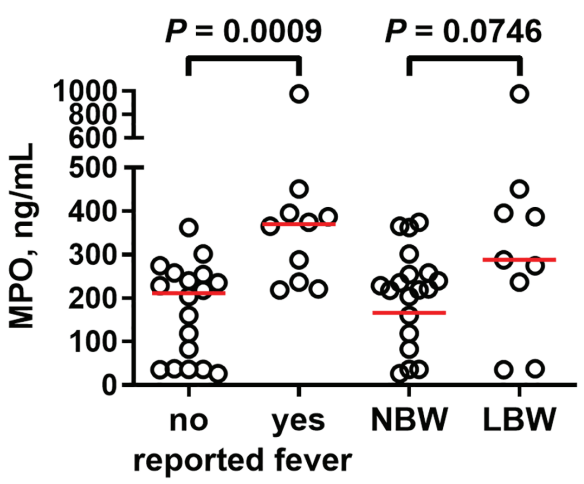

FIGURE 4 | Placental blood MPO levels increase in chronic, inflammatory placental malaria, together with reduced birth weight. (A) MPO measured in placental plasma by ELISA from primigravid women with and without PM stratified by placental histopathological status (see Methods). (B) Infant birth weight from the same women is similarly stratified. (C) MPO levels collectively analyzed by Spearman's correlation test with percent placental leukocytes (WBCs) bearing engulfed hemozoin. (D) Placental MPO levels measured by ELISA assessed for relationships with self-reported fever and infant birth weight. Statistics by Kruskal-Wallis test with post-hoc group-wise comparisons by Dunn's multiple comparisons test. $\mathrm{PM}$ - = placental malaria negative $(n=10)$; $\mathrm{A}=$ acute infection $(n=4) ; C=$ chronic infection $(n=5)$; $C l=$ chronic inflammatory infection $(n=9)$; NBW= normal birth weight $(n=19)$; LBW = low birth weight $(n=9)$; no self-reported fever $(n=18)$, reported fever $(n=10)$. 


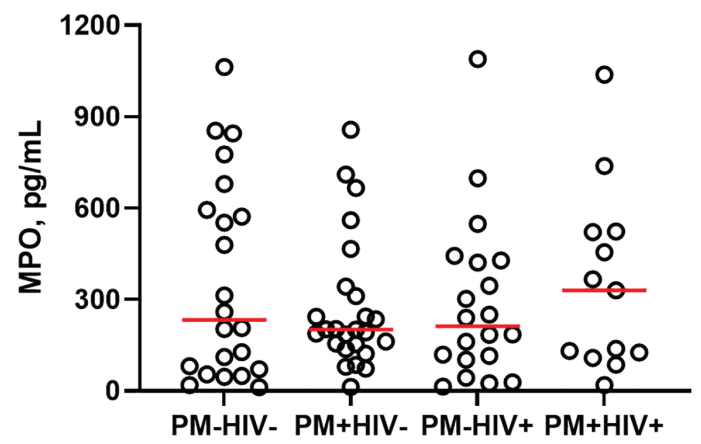

B

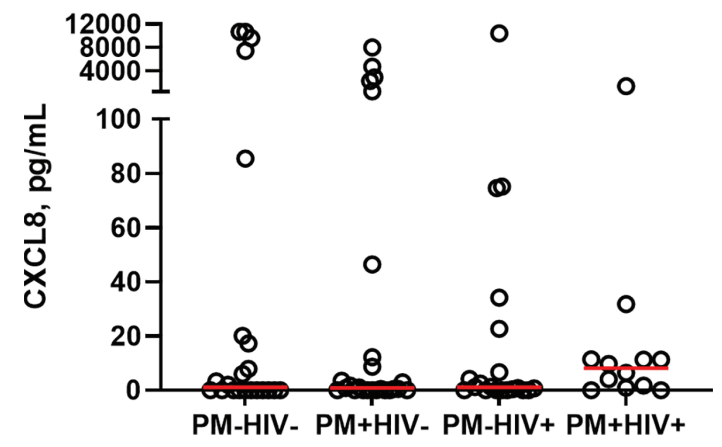

FIGURE 5 | Peripheral blood MPO and CXCL8 levels do not change as a function of placental malaria and HIV seropositivity. Peripheral plasma samples from paucigravid women were analyzed for (A) MPO and (B) CXCL8 levels by bead array. No statistically significant differences among the groups are evident (Kruskal-Wallis test with post-hoc group-wise comparisons by Dunn's multiple

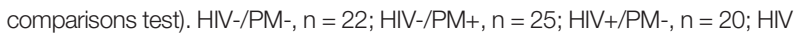
$+/ P M+, n=14$ (MPO), n=13 (CXCL8.) Groups as defined in Figure 2.

immunohistochemistry. MPO+ cells are frequently observed in these placentae, even in the absence of PM (Figures 8A-D). Frequency (Figure 8E) and intensity of MPO expression (Figure 8F), however, tend to be enhanced in PM+HIV- but not $\mathrm{PM}+\mathrm{HIV}+$ tissues. Probing for MPO by western blot of proteins derived from whole placental tissue may serve as a proxy for intensity of MPO expression, but preliminary analysis thereto does not reveal compelling evidence for influence of protein levels by infection status (Supplemental Figures 4A, C). Similarly, NE protein levels in whole placental tissue extracts are independent of infection status (Supplemental Figure 4B, D).

\section{Plasma Markers of NETosis Are Not Affected by PM}

Although NETosis has been linked to severe malaria in nonpregnant patients $(38,56,57)$, this mechanism has not to our knowledge been explored in PM. Using detection of nonspecific (cell-free DNA; Supplemental Figure 5A) and known markers of NET formation (NE-DNA, Supplemental Figure 5B; cell-free histones, Supplemental Figure 5C), no evidence of significant PM-induced NETosis in placental plasma is observed in HIV- primigravidae (as in Figure 4), regardless of placental histopathological status. Similarly, citrullinated histone $\mathrm{H} 3$ (citH3), an additional marker of NET formation, does not differ in paucigravid placental plasma as a function of PM regardless of HIV infection (Supplemental Figure 6A), although elevated levels are evident in two PM+ women. Nonetheless, citrullinated histone H3 levels tend to positively correlate with placental granulocyte count (Supplemental Figure 6B).

\section{In Situ Evidence for Netosis in Placental Tissue}

As an alternate indicator of NETosis, fixed placental tissue was probed by immunohistochemistry for citH3. Some weakly positive cells are evident in the intervillous space, and, surprisingly, occasional stronger staining is seen in syncytiotrophoblast (Supplemental Figure 7A, B). Extracellular evidence of citH3, structures that would be consistent with NETosis, however, is rarely observed (Supplemental Figure 4B).

Although attempts to identify soluble components of NETosis in placental plasma and in situ in fixed, paraffin-embedded placental tissue does not provide compelling evidence of PM with or without HIV co-infection as a driver of placental NETosis, it is not possible to conclude that this process does not occur in PM, since sample collection, processing and storage, for example, could impede such detection. As an alternate approach, placental tissues flash-frozen in OCT were assessed by immunofluorescence staining for MPO, NE and DNA. In most samples, regardless of infection status, structures that are suggestive of NETs are evident (Figure 9; Supplemental Figure 8). The presumptive NETs are highly pleomorphic. Some structures are composed of single cells in the intervillous space that have streaky, comet-like nuclei and cytoplasm containing blue fluorescence (DNA) that colocalizes with green fluorescence (MPO) and red fluorescence (NE) (Figures 9M-P, R-T). Most frequently, the NETs are characterized by small to large aggregates of two or more pleomorphic cells with indistinct cell limits and pleomorphic nuclei encroached in a large $\mathrm{MPO}+/ \mathrm{NE}+$ cytoplasm (Figures 9M-O, Q-S). Frequently, the cytoplasmic projections colocalize with MPO, NE and DNA material (Figures 9M-O, Q-S). These presumptive NETs are observed in maternal intervillous blood spaces, within the villus stroma, and occasionally inside the fetal vasculature (Figures 9S, T).

The small sample size of this experiment impacts statistical power; however, counts of singly stained $\mathrm{MPO}+, \mathrm{NE}+$ and MPO +/NE+ double stained cells do not vary with PM, including with stratification by HIV serostatus (Supplemental Figures 8A-C). Small, non-NETosing neutrophils (double MPO+/NE+, <102 $\mu^{2}$ ) tend to be more numerous with PM (median, IQR, PM-: 12, 4.5 - 60; PM+: 22, $18-41 ; P=0.0928)$ whereas larger putatively NETosing $\mathrm{MPO}+\mathrm{NE}+$ cells are unchanged (median, IQR, PM-: 9.0, 2.0 - 35; PM+: 19, 15 - 34; $P=0.3735)$. Further stratification by HIV infection status yields no significant differences between the groups for small and large cells, including assessment of large NETosing cells as a percent of all $\mathrm{MPO}+/ \mathrm{NE}+$ cells (Supplemental Figures 8D-F). Counts of $\mathrm{MPO}+\mathrm{NE}+$ cells, including those classified as large, positively correlate with placental levels of CXCL8 (Figures 10A, B), with a similar tendency for small $\mathrm{MPO}+/ \mathrm{NE}+$ neutrophils 


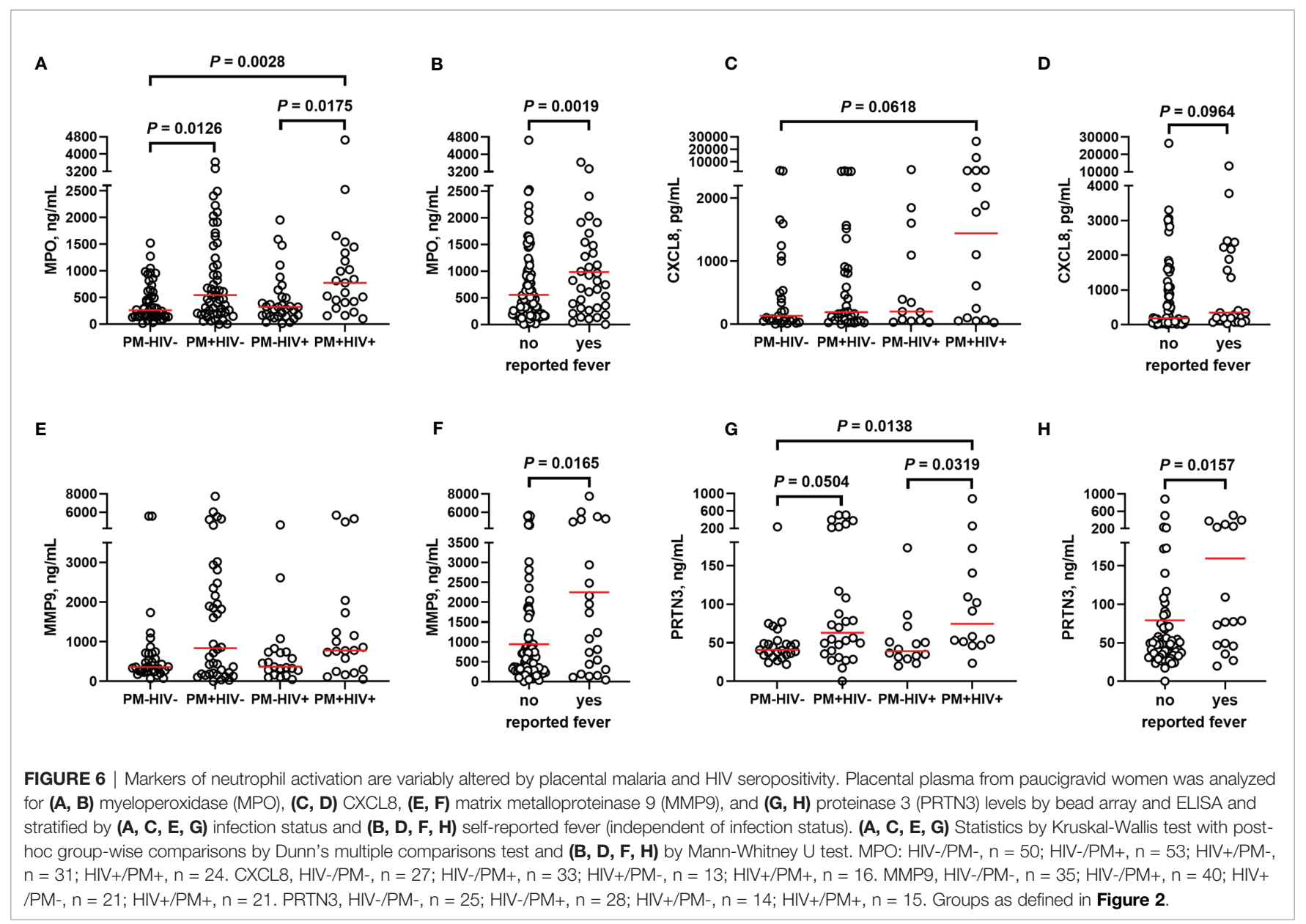

(Figure 10C). Likewise, weak positive correlations are observed between MMP9 and MPO+/NE+ cells as well as small neutrophils (Figures 10D, F) but not between MMP9 and large cell count (Figure 10E). Placental levels of MPO are unrelated to these cell counts (Supplemental Figure 9).

\section{DISCUSSION}

In this study, we analyzed maternal peripheral and placental granulocyte levels as well as markers of neutrophil activation, including NET-specific markers and structures, in women with and without PM and HIV infection at the time of delivery. The results show that maternal peripheral granulocyte counts decrease with PM in the presence and absence of pre-existing HIV infection. Although a differential to discern neutrophil counts among the granulocytes was not performed, these findings are consistent with previous work that reported reduced neutrophil counts in malariainfected pregnant compared to uninfected women $(3,76)$. A study in rhesus monkeys (Macaca mulatta) infected with P. coatneyi also showed a significant decrease in neutrophil levels starting at gestation week 9 (77). This contrasts with the observation that neutrophil counts are enhanced with HIV infection in pregnant women (78). Our results suggest that PM overcomes this apparent HIV-driven neutrophilia, since HIV seropositive women with PM

TABLE 2 | Correlation matrix of placental markers of neutrophil activation.

\begin{tabular}{|c|c|c|c|c|c|c|c|c|}
\hline & \multicolumn{2}{|l|}{ MPO } & \multicolumn{2}{|l|}{ MMP9 } & \multicolumn{2}{|l|}{ PRTN3 } & \multicolumn{2}{|l|}{ CXCL8 } \\
\hline & $\mathbf{r}$, IQR $^{*}$ & $P$ & r, IQR & $\boldsymbol{P}$ & r, IQR & $P$ & r, IQR & $P$ \\
\hline MPO & 1 & - & $0.7287,0.6273-0.8058$ & $<0.0001$ & $0.9179,0.8737-0.9471$ & $<0.0001$ & $0.4485,0.2002-0.6426$ & 0.0006 \\
\hline MMP9 & $0.7287,0.6273-0.8058$ & $<0.0001$ & 1 & - & $0.7626,0.6500-0.8424$ & $<0.0001$ & $0.3797,0.0804-0.6161$ & 0.0120 \\
\hline PRTN3 & $0.9179,0.8737-0.9471$ & $<0.0001$ & $0.7626,0.6500-0.8424$ & $<0.0001$ & 1 & - & $0.4106,0.0615-0.6701$ & 0.0196 \\
\hline CXCL8 & $0.4485,0.2002-0.6426$ & 0.0006 & $0.3796,0.0804-0.6161$ & 0.0120 & $0.4106,0.0615-0.6701$ & 0.0196 & 1 & - \\
\hline
\end{tabular}

*Data represent results of Spearman's test with IQR, interquartile range. 
A

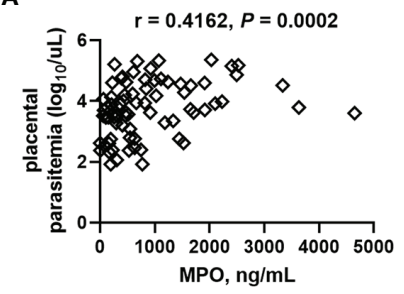

E

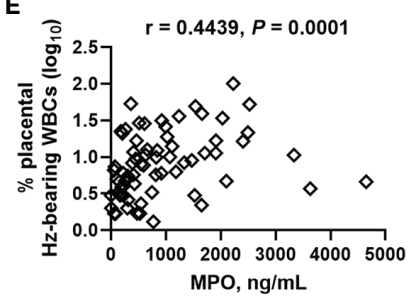

B

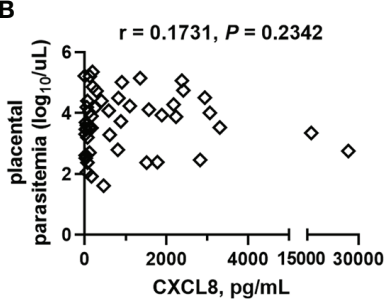

F

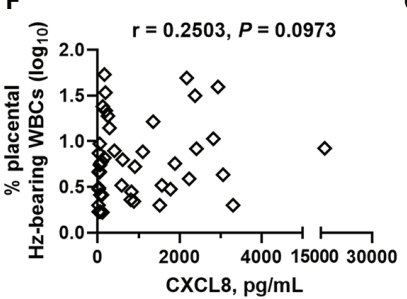

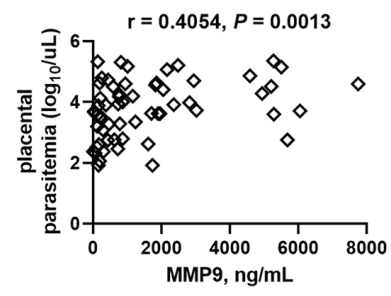

G

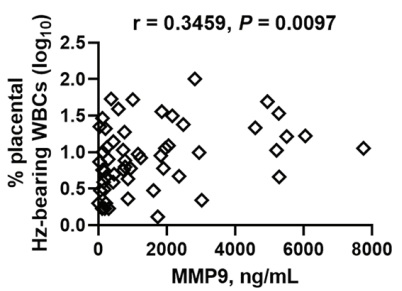

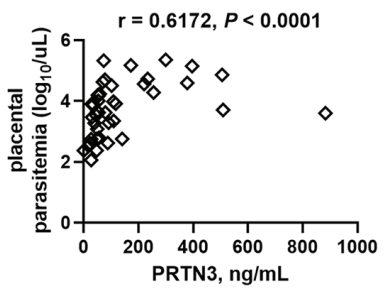

H

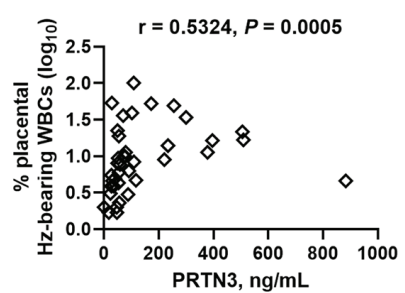

FIGURE 7 | Placental blood MPO, MMP9, and PRTN3 levels positively correlate with placental parasite density and hemozoin-bearing white blood cells. (A, E) MPO, (B, F) CXCL8, (C, G) MMP9, and (D, H) PRTN3 levels measured by bead array in plasma are collectively analyzed by Spearman's correlation test with (A-D) thick smear placental parasite density (log transformed) and $(\mathbf{E}-\mathbf{H})$ percent placental WBCs bearing engulfed hemozoin (log transformed). $(\mathbf{A}), \mathrm{n}=\mathbf{7 7}$; $(\mathbf{B})$, $\mathrm{n}=49$; (C), $n=61 ;$ (D), $n=43 ;($ E), $n=73 ;(\mathbf{F}), n=47 ;(G), n=57 ;(H), n=40$.

have significantly suppressed granulocyte counts in the peripheral blood.

Contrary to expectation, no differences in granulocyte counts in the placenta are evident in this cohort of women. However, the enhanced ratios of placental to peripheral blood granulocyte numbers at the population level support the conclusion that during PM and PM/HIV co-infection, granulocytes accumulate in the placenta at the expense of the periphery, or, at minimum, are relatively more stable in the placenta. The physiological control of this phenomenon is worthy of further investigation, particularly given our observation that overall, granulocytes make up a lower proportion of total leukocytes in the placenta than in the peripheral blood and thus may be differentially regulated in these two blood spaces. Neutrophils are a key component of the normal process of labor, with accumulation of these cells in the uterine wall; the reductions observed here may be indicative of an exodus of neutrophils from the intervillous space to the myometrium [reviewed in (79)]. Despite the tendency toward lower granulocyte percentages and counts in placental relative to peripheral blood in the absence of infection, pairwise comparison at the individual patient level shows an overall tendency for granulocyte counts in placenta to increase uniquely with $\mathrm{PM} / \mathrm{HIV}$ co-infection. However, granulocytes as a percent of total WBCs in the placenta are significantly reduced with co-infection. This may indicate that the massive overall increase in placental WBCs seen in this group (Supplemental Table 1) is heavily attributable to other cell subsets, likely monocytes (20).

Other researchers have reported significant accumulation of neutrophils in the placenta with $\operatorname{PM}(19,20)$. What may be driving accumulation or preservation of these cells in the maternal placental blood, and why the current study shows placental granulocyte count stability but not accumulation with $\mathrm{PM}$ is unclear. Aside from the obvious differences in methodology and cell identification, placental granulocyte levels as measured here appear to be influenced by infection intensity, as counts positively correlate with the percent of placental WBCs bearing phagocytosed Hz. Thus, differences across studies could also be due to differences in infection intensity or chronicity. In general, local production of chemokines, including CXCL8, a factor that promotes neutrophil chemotaxis (80), may be an important determining factor in granulocyte/neutrophil presence in the intervillous blood, as is the case for recruitment to the uterus at parturition [reviewed in (79)]. Importantly, CXCL8 is elevated in PM+HIV+ placentae. The source of CXCL8 in the placenta that might participate in this response is not clear but could be maternal monocytes $(22,26)$, fetal syncytiotrophoblast $(3,22,81,82)$, or uterine/decidual stromal cells (83).

Previous studies have indicated that neutrophils may play a pathogenic role in PM and could serve as prognostic markers for malaria-associated low birth weight (18). We report that in this population of parturient women, granulocyte counts do not associate with infant birth outcomes. This may be due to inadequate sample size, lack of differential analysis to directly count neutrophils, or may be related to the overall patient recruitment strategy, which excluded complicated pregnancies and deliveries and health issues other than malaria and HIV infections. Because an interesting relationship between neutrophils and malaria parasites is emerging [reviewed in (36)] and neutrophils are key cells at multiple stages of normal and abnormal pregnancy [reviewed in (79)], it is imperative for future studies to definitively identify neutrophils in the granulocyte population, and to further consider neutrophil 

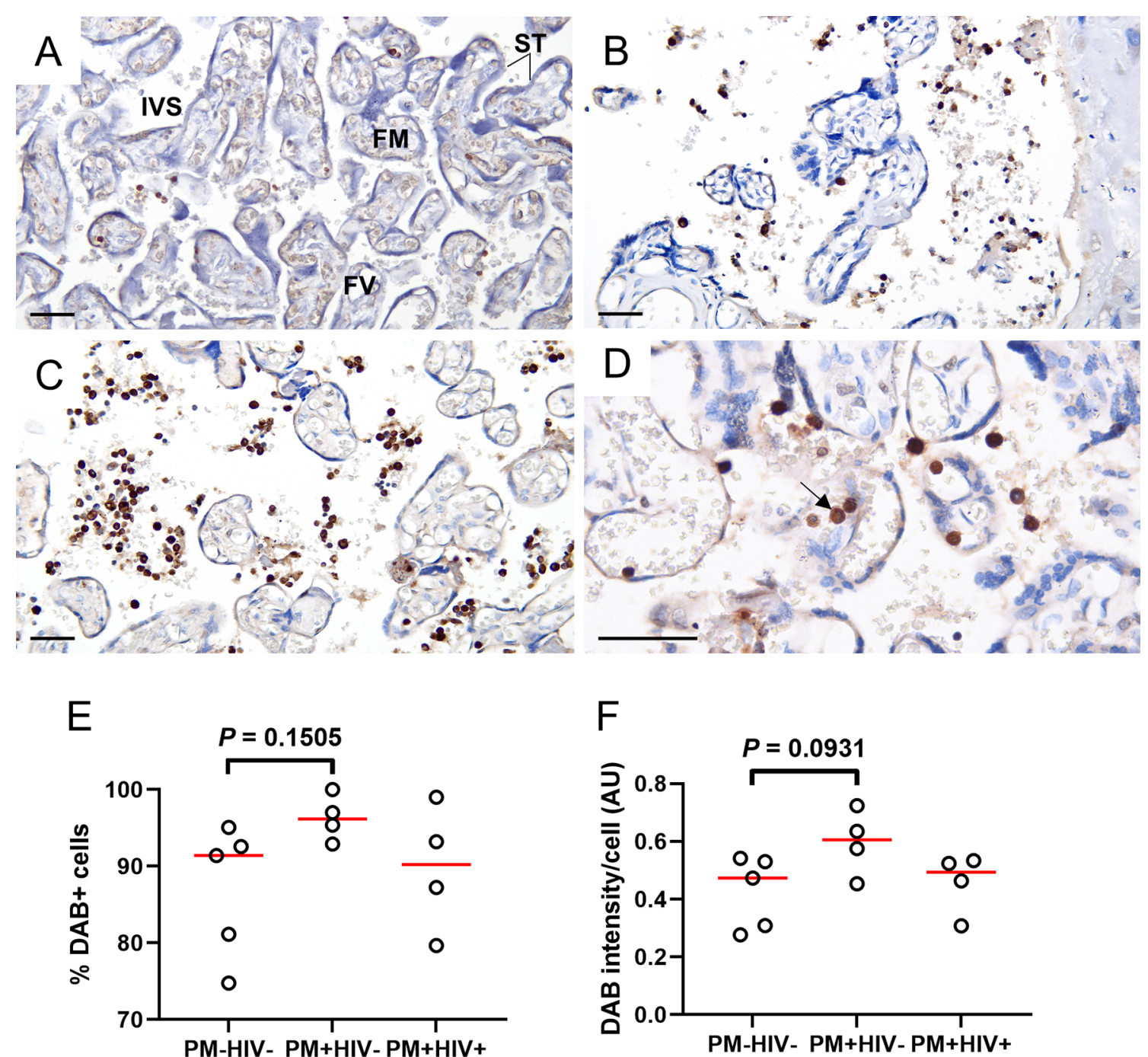

FIGURE 8 | Placental WBCs from PM+HIV- women show more robust MPO expression by immunohistochemistry relative to uninfected and co-infected women. Frequency and intensity of MPO staining is lower in (A) uninfected placenta and (B) PM+HIV+ placenta relative to (C) PM+HIV- placenta. (D) Segmented nucleus clearly delineates MPO staining in a neutrophil (arrow). ST, syncytiotrophoblast; FM, fetal mesenchyme; FV, fetal vessel; IVS, intervillous space. Scale bars represent 50 mm. (E) Percent cells expressing MPO weakly tends to be higher in PM+HIV- relative to uninfected women. (F) MPO staining intensity tends to be higher in PM+ HIV- relative to uninfected women. Statistics by Kruskal-Wallis test with post-hoc group-wise comparisons by Dunn's multiple comparisons test. PM-/HIV-, $\mathrm{n}=5$; $\mathrm{PM}+/ \mathrm{HIV}-, \mathrm{n}=4 ; \mathrm{PM}+/ \mathrm{HIV}+, \mathrm{n}=4$. Groups as defined in Figure 2.

subsets and functional parameters to discern potential relationships with pathogenic outcomes of PM.

One of the many consequences of neutrophil activation is the secretion of granules containing MPO, MMP9, NE, and PRTN3. Neutrophils produce massive amounts of these proteins, in the case of MPO, representing $5 \%$ of the total cellular protein (84). Our data show for the first time that placental blood MPO and PRTN3 levels are elevated with PM in both HIV- and HIV+ paucigravid women relative to PM-HIV- women. It was unexpected to find that none of these markers correlates with placental granulocyte counts, emphasizing the need for further work to definitively identify the source of these factors in placental plasma and fully characterize neutrophil function in
PM. Importantly, observations of MPO in fixed placental tissue sections suggest that this factor may be produced by both intervillous neutrophils and monocytes, yet most MPOexpressing cells observed by immunofluorescence are costained for NE, identifying them as neutrophils.

Placental levels of MPO, MMP9, and PRTN3 all positively correlate with placental parasitemia as well as placental hemozoin bearing WBCs, suggesting that production is enhanced by chronic infection. Since MPO attenuates pathogen clearance during $P$. yoelii nonlethal infection (85), it is tempting to speculate that this enzyme may inhibit parasite clearance in PM as well. In an initial pilot study, we found placental blood MPO levels to be increased significantly with 

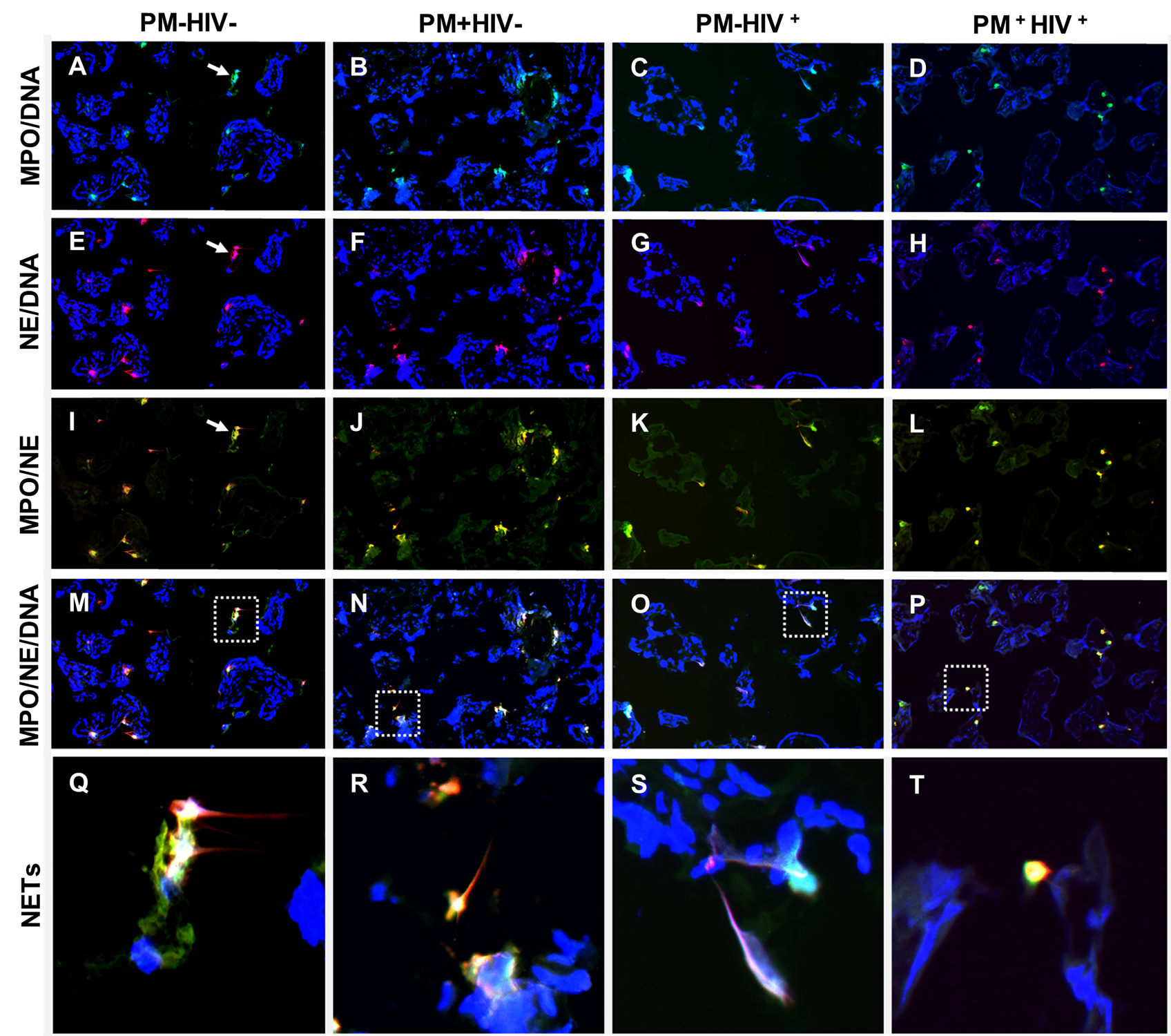

FIGURE 9 | Detection of NETs by immunfluorescence in placental tissue. Immunolocalization of MPO (green), NE (red) in term placenta. The DNA was labeled with Hoescht 33342 (blue). (A, E, I, M, Q) uninfected placenta; (B, F, J, N, R) PM+HIV- placenta; (C, G, K, O, S) PM-HIV+ placenta; and (D, H, L, P, T) PM+HIV+ placenta. The first row (A-D) shows the colocalization of MPO with DNA, the second row (E-H), colocalization of NE and DNA, the third row (I-L), colocalization of MPO and NE and the fourth row (M-P), colocalization of MPO, NE and DNA. The last row shows in higher magnification the dotted areas in panels (M-P) that contain putative NET-like structures (Q-T). Arrows in panels (A, E, I) indicate NET-like structures. Groups are as defined in Figure 2.

chronic, inflammatory PM in primigravidae. MPO is associated with vascular dysfunction (86) and underlies the pathophysiology of numerous vascular inflammatory diseases including arteriosclerosis and coronary artery disease $(87,88)$. Inflammation and endothelial dysfunction are characteristics of preeclampsia, and increased MPO levels in placental and peripheral circulation in preeclamptic women have been described $(89,90)$. The extent to which PM and PM/HIV coinfection may contribute to preeclampsia via MPO production or modification of other neutrophil functions remains to be determined. This may be an exciting avenue to pursue given increasing evidence that malaria predisposes women to this hypertensive disorder $(91,92)$.

Elevated neutrophil activation, as evidenced by higher plasma concentrations not only of MPO but also of PRTN3 and NE, is associated with severe pediatric malaria (39). Likewise, MMP9, an endopeptidase released by neutrophils and monocytes, is implicated in the pathogenesis of severe malaria (93-95). An MMP9 polymorphism protects against PM, further implicating an important role for this enzyme in P. falciparum infection (96). Importantly, MPO, MMP9 and PRTN3 levels in the placenta associate with self-reported fever in this cohort of parturient 


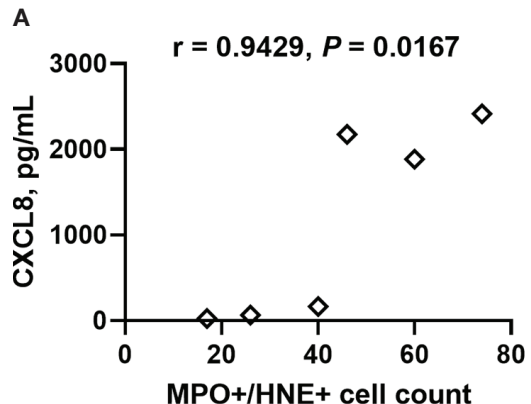

D

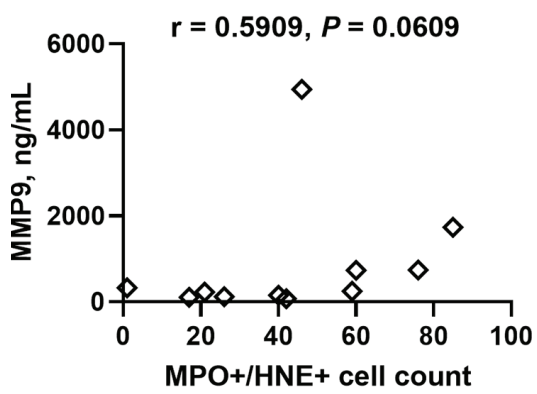

B

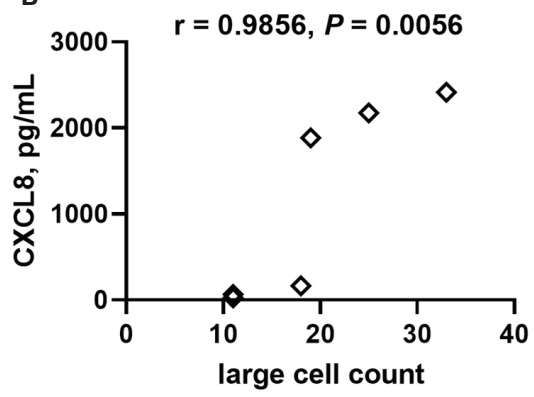

E

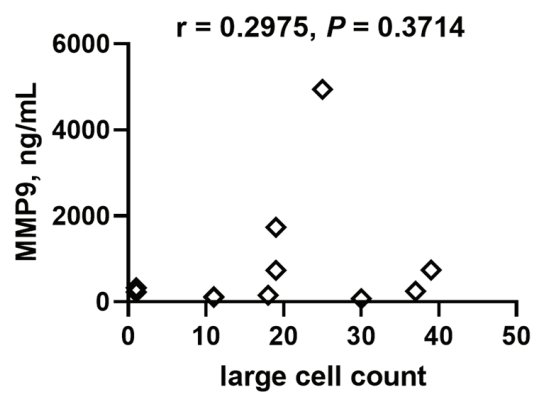

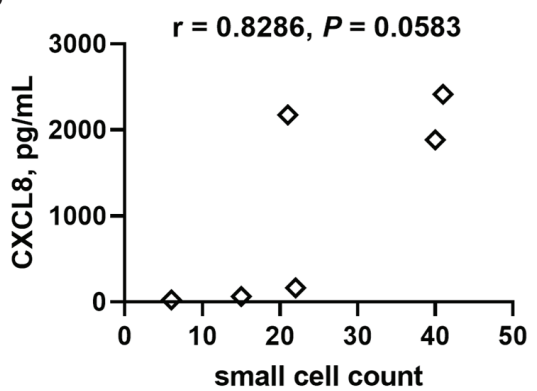

$\mathbf{F}$

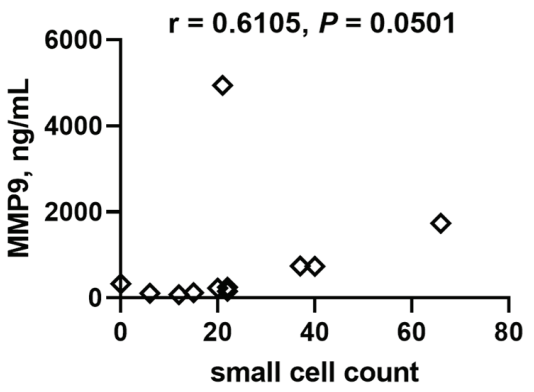

FIGURE 10 | Correlation analysis of CXCL8 and MMP9 with neutrophils in placental tissue. Counts of neutrophils detected in frozen cryosections as (A, D) MPO+ /NE+, and MPO+/NE+ cells stratified by size as (B, E) large: $>102 \mu \mathrm{m}^{2}$, and (C, F) small: $<102 \mu \mathrm{m}^{2}$ collectively correlated with placental plasma levels of (A-C) CXCL8 and (D-F) MMP9. Cell counts determined by analysis of immunofluorescence of tissues. Statistics by Spearman's correlation test. PM-/HIV-, $n=5 ;$ PM+ $/ H I V-, n=5 ; P M-/ H I V+, n=4 ; P M+/ H I V+, n=4$. Groups as defined in Figure 2.

women. However, while pilot data in HIV seronegative primigravidae suggest a tendency for placental MPO to be higher in women with low birth weight infants, in a larger cohort of paucigravid malaria-exposed women that also considered HIV infection, no relationship with birth weight or gestational age emerges for any of these markers. This is unexpected given that the factors do correlate with parameters (placental parasite density and Hz-bearing WBCs) that are typically associated with poor outcomes in PM. Indeed, Hz-bearing neutrophils in the peripheral blood of pregnant women predict low birth weight (18). While additional work will be required to resolve this discrepancy, these results suggest that the mechanism by which neutrophils mediate poor birth outcomes may not be directly related to the release of neutrophil granules in the placental blood space. One potential alternate mechanism may be downstream effects of these factors, which were not measured here. High concentrations of neutrophilderived antimicrobial compounds can make these cells detrimental to the host (97-99). For example, activated neutrophils exacerbate preeclampsia by releasing ROS (100-105). Of note, MPO catalyzes the formation of aggressive reactive oxygen intermediates, including hypochlorous, hypobromous, and hypothiocyanous acids, respectively $(106,107)$, which contribute to oxidative killing (108). Oxidative stress is a feature of PM $(43,44)$, but the extent to which neutrophils contribute to it remains to be established.

Contrary to expectation, this study finds no evidence of a relationship between PM and levels of soluble markers of NETosis in the placenta. Similarly, while structures consistent with NETs (MPO, NE, and DNA co-localization) are observed in the intervillous space, a relationship with PM is not evident. Alternatively, non-activated, resting, "small" neutrophils tend to be elevated with PM in this study. Because NETs have been observed in the placental intervillous space in pregnancies complicated by preeclampsia $(103,105)$, and given parallels between PM and preeclampsia, it was our expectation that NETosis would be enhanced in placentae of infected women. While further research designed specifically to address this question is warranted, it is tempting to speculate that NETosis may be subject to unique and as yet poorly understood control mechanisms in the placenta that are not specifically activated or perturbed by PM. The overall reduction of granulocyte counts in the placenta relative to the peripheral blood hints at this possibility.

In conclusion, the present study demonstrates that PM and $\mathrm{PM} / \mathrm{HIV}$ co-infection perturb granulocyte levels, and soluble signatures of neutrophil activation associate with indicators of PM infection and associated symptoms. The findings do not authoritatively distinguish between a protective or pathogenic role for neutrophils or products of their activation, nor is an association of PM with NETosis established. Further exploration of neutrophil function in the context of malaria and HIV in pregnant women, particularly direct assessment of activity, is required to fill remaining gaps in knowledge. 


\section{DATA AVAILABILITY STATEMENT}

The original contributions presented in the study are included in the article/Supplementary Material. Further inquiries can be directed to the corresponding author.

\section{ETHICS STATEMENT}

The study supporting collection of samples used in this report was approved by the Kenya Medical Research Institute Ethical Review Committee, and the Centers for Disease Control and Prevention and the University of Georgia Institutional Review Boards. All study participants provided written informed consent before enrollment and procedures and instruments involving human subjects, sample collection and data analysis, processing, and testing were approved throughout the conduct of patient recruitment. All samples and data are anonymized.

\section{AUTHOR CONTRIBUTIONS}

JMM, LJO, BR, and DS conceived and designed the experiments. LA, JDM, JMM, SM, and SO coordinated sample and clinical data collection. FA, JMM, LJO, SO, BR, BNR, and DS performed the experiments. LJO performed the Qupath analysis and prepared micrographs. JMM, LJO, BNR, and DS prepared the figures and tables. JMM performed descriptive statistical analyses. JMM, LJO, and DS wrote the manuscript. JV provided logistical and infrastructural support for sample collection, processing, storage and shipment, and facilitated local ethical reviews in Kenya. All authors (with the exception of JV, deceased) contributed to the article and approved the submitted version.

\section{FUNDING}

This work was supported by the National Institutes of Health grants R01 AI050240 and R21 AI111242, and research support

\section{REFERENCES}

1. Bauserman M, Conroy AL, North K, Patterson J, Bose C, Meshnick S. An Overview of Malaria in Pregnancy. Semin Perinatol (2019) 43(5):282-90. doi: 10.1053/j.semperi.2019.03.018

2. Ayres Pereira M, Mandel Clausen T, Pehrson C, Mao Y, Resende M, Daugaard M, et al. Placental Sequestration of Plasmodium Falciparum Malaria Parasites Is Mediated by the Interaction Between VAR2CSA and Chondroitin Sulfate A on Syndecan-1. PloS Pathogens (2016) 12(8): e1005831. doi: 10.1371/journal.ppat.1005831

3. Bostrom S, Schmiegelow C, Abu Abed U, Minja DTR, Lusingu J, Brinkmann V, et al. Neutrophil Alterations in Pregnancy-Associated Malaria and Induction of Neutrophil Chemotaxis by Plasmodium Falciparum. Parasite Immunol (2017) 39(6):1-6. doi: 10.1111/pim.12433

4. Rogerson SJ, Mwapasa V, Meshnick SR. Malaria in Pregnancy: Linking Immunity and Pathogenesis to Prevention. Am J Trop Med Hygiene (2007) 77(6 Suppl):14-22. doi: 10.4269/ajtmh.77.6.suppl.14

5. Rogerson SJ, Pollina E, Getachew A, Tadesse E, Lema VM, Molyneux ME. Placental Monocyte Infiltrates in Response to Plasmodium Falciparum Malaria from the University of Florida to JMM. The content is solely the responsibility of the authors and does not necessarily represent the official views of the National Institute of Allergy and Infectious Diseases (NIAID) or the National Institutes of Health. The funders had no role in study design, data collection and analysis, decision to publish, or preparation of the manuscript.

\section{ACKNOWLEDGMENTS}

We thank the parturient women and Labour Ward staff at New Nyanza Provincial General Hospital, Kisumu and Siaya District Hospital, Siaya, Kenya, and the Kenya-based UGA/KEMRI team, including Meshak Auma, Mary Kibatha, Jackline Midoro, Brisson Muia, Philip Naluande, Benson Odhiambo, Fenner Odhiambo, Dorothy Odidi, Milka Okwach, Dickens Olang, Francis Omwalo, Elkana Ondere, Godfrey Owenga, Rose Oyucho, Moses Sichangi, and Benson Vibhakar, without whose participation, active support and dedication this study would not have been possible.

\section{SUPPLEMENTARY MATERIAL}

The Supplementary Material for this article can be found online at: https://www.frontiersin.org/articles/10.3389/fimmu.2021.682668/ full\#supplementary-material

Supplementary Table 1 | Pairwise comparison of peripheral and placental white blood cell (WBC) and granulocyte counts. PM = placental malaria; HIV = human immunodeficiency virus. Data are shown in graphical form in Supplemental Figure 2A, and Supplemental Figure 2B.

Supplementary Table 2 | Granulocyte numbers as a function of infant birth weight and gestational age at birth. NBW, normal birth weight, LBW, low birth weight; TB, term birth; PTB, preterm birth.

Infection and Their Association With Adverse Pregnancy Outcomes. Am J Trop Med Hygiene (2003) 68(1):115-9. doi: 10.4269/ajtmh.2003.68.1.0680115

6. Serghides L, Finney CA, Ayi K, Loutfy M, Kain KC. Chronic HIV Infection Impairs Nonopsonic Phagocytosis of Malaria Parasites. J Acquir Immune Defic Syndr (2015) 68(2):128-32. doi: 10.1097/QAI.0000000000000427

7. Steketee RW, Wirima JJ, Bloland PB, Chilima B, Mermin JH, Chitsulo L, et al. Impairment of a Pregnant Woman's Acquired Ability to Limit Plasmodium Falciparum by Infection With Human Immunodeficiency Virus Type-1. Am J Trop Med Hygiene (1996) 55(1 Suppl):42-9. doi: 10.4269/ajtmh.1996.55.42

8. Parise ME, Ayisi JG, Nahlen BL, Schultz LJ, Roberts JM, Misore A, et al. Efficacy of Sulfadoxine-Pyrimethamine for Prevention of Placental Malaria in an Area of Kenya With a High Prevalence of Malaria and Human Immunodeficiency Virus Infection. Am J Trop Med Hygiene (1998) 59 (5):813-22. doi: 10.4269/ajtmh.1998.59.813

9. Verhoeff FH, Brabin BJ, Hart CA, Chimsuku L, Kazembe P, Broadhead RL. Increased Prevalence of Malaria in HIV-Infected Pregnant Women and its Implications for Malaria Control. Trop Med Int Health (1999) 4(1):5-12. doi: 10.1046/j.1365-3156.1999.00349.x 
10. van Eijk AM, Ayisi JG, ter Kuile FO, Misore A, Otieno JA, Kolczak MS, et al. Human Immunodeficiency Virus Seropositivity and Malaria as Risk Factors for Third-Trimester Anemia in Asymptomatic Pregnant Women in Western Kenya. Am J Trop Med Hygiene (2001) 65(5):623-30. doi: 10.4269/ajtmh.2001.65.623

11. Perrault SD, Hajek J, Zhong K, Owino SO, Sichangi M, Smith G, et al. Human Immunodeficiency Virus Co-Infection Increases Placental Parasite Density and Transplacental Malaria Transmission in Western Kenya. Am J Trop Med Hygiene (2009) 80(1):119-25. doi: 10.4269/ajtmh.2009.80.119

12. Bloland PB, Wirima JJ, Steketee RW, Chilima B, Hightower A, Breman JG. Maternal HIV Infection and Infant Mortality in Malawi: Evidence for Increased Mortality Due to Placental Malaria Infection. AIDS (1995) 9 (7):721-6. doi: 10.1097/00002030-199507000-00009

13. Mwapasa V, Rogerson SJ, Molyneux ME, Abrams ET, Kamwendo DD, Lema VM, et al. The Effect of Plasmodium Falciparum Malaria on Peripheral and Placental HIV-1 RNA Concentrations in Pregnant Malawian Women. AIDS (2004) 18(7):1051-9. doi: 10.1097/00002030-200404300-00014

14. Briand V, Badaut C, Cot M. Placental Malaria, Maternal HIV Infection and Infant Morbidity. Ann Trop Paediatr (2009) 29(2):71-83. doi: 10.1179/ 146532809X440699

15. Mockenhaupt FP, Bedu-Addo G, von Gaertner C, Boye R, Fricke K, Hannibal I, et al. Detection and Clinical Manifestation of Placental Malaria in Southern Ghana. Malaria J (2006) 5:119. doi: 10.1186/1475-2875-5-119

16. Naseem S, Anwar S, Ihsanullah M. Outcome and Complications of Malaria in Pregnancy. Gomal J Med Sci (2004) 6:98-101.

17. Nielson KS, Melo M, Vanella I. Primary HIV Infection During Pregnancy: High Rate of HIV-1 MTCT in a Cohort of Patients in South Brazil. Retrovirology (2008) 5(1). doi: 10.1186/1742-4690-5-S1-O1

18. Chua CL, Robinson LJ, Baiwog F, Stanisic DI, Hamilton JA, Brown GV, et al. High Numbers of Circulating Pigmented Polymorphonuclear Neutrophils as a Prognostic Marker for Decreased Birth Weight During Malaria in Pregnancy. Int J Parasitol (2015) 45(2-3):107-11. doi: 10.1016/j.ijpara.2014.12.002

19. Okamgba OC, Ifeanyichukwu MO, Ilesanmi AO, Chigbu LN. Variations in the Leukocyte and Cytokine Profiles Between Placental and Maternal Circulation in Pregnancy-Associated Malaria. Res Rep Trop Med (2018) 9:1-8. doi: 10.2147/RRTM.S137829

20. Ordi J, Menendez C, Ismail MR, Ventura PJ, Palacin A, Kahigwa E, et al. Placental Malaria Is Associated With Cell-Mediated Inflammatory Responses With Selective Absence of Natural Killer Cells. I Infect Dis (2001) 183(7):1100-7. doi: 10.1086/319295

21. Ordi J, Ismail MR, Ventura PJ, Kahigwa E, Hirt R, Cardesa A, et al. Massive Chronic Intervillositis of the Placenta Associated With Malaria Infection. Am J Surg Pathol (1998) 22(8):1006-11. doi: 10.1097/00000478-199808000-00011

22. Moormann AM, Sullivan AD, Rochford RA, Chensue SW, Bock PJ, Nyirenda T, et al. Malaria and Pregnancy: Placental Cytokine Expression and Its Relationship to Intrauterine Growth Retardation. J Infect Dis (1999) 180(6):1987-93. doi: 10.1086/315135

23. Chaisavaneeyakorn S, Moore JM, Othoro C, Otieno J, Chaiyaroj SC, Shi YP, et al. Immunity to Placental Malaria. IV. Placental Malaria Is Associated With Up-Regulation of Macrophage Migration Inhibitory Factor in Intervillous Blood. J Infect Dis (2002) 186(9):1371-5.

24. Chaisavaneeyakorn S, Moore JM, Mirel L, Othoro C, Otieno J, Chaiyaroj SC, et al. Levels of Macrophage Inflammatory Protein 1 Alpha (MIP-1 Alpha) and MIP-1 Beta in Intervillous Blood Plasma Samples From Women With Placental Malaria and Human Immunodeficiency Virus Infection. Clin Diagn Lab Immunol (2003) 10(4):631-6. doi: 10.1128/cdli.10.4.631-636.2003

25. Chaisavaneeyakorn S, Lucchi N, Abramowsky C, Othoro C, Chaiyaroj SC, Shi YP, et al. Immunohistological Characterization of Macrophage Migration Inhibitory Factor Expression in Plasmodium FalciparumInfected Placentas. Infect Immun (2005) 73(6):3287-93. doi: 10.1128/ IAI.73.6.3287-3293.2005

26. Abrams ET, Brown H, Chensue SW, Turner GD, Tadesse E, Lema VM, et al. Host Response to Malaria During Pregnancy: Placental Monocyte Recruitment Is Associated With Elevated Beta Chemokine Expression. J Immunol (2003) 170(5):2759-64. doi: 10.4049/jimmunol.170.5.2759

27. Suguitan AL Jr, Leke RG, Fouda G, Zhou A, Thuita L, Metenou S, et al. Changes in the Levels of Chemokines and Cytokines in the Placentas of Women With Plasmodium Falciparum Malaria. J Infect Dis (2003) 188 (7):1074-82. doi: 10.1086/378500
28. Ambayya A, Su AT, Osman NH, Nik-Samsudin NR, Khalid K, Chang KM, et al. Haematological Reference Intervals in a Multiethnic Population. PloS One (2014) 9(3):e91968. doi: 10.1371/journal.pone.0091968

29. Sato R, Ikuma M, Takagi K, Yamagishi Y, Asano J, Matsunaga Y, et al. Exposure of Drugs for Hypertension, Diabetes, and Autoimmune Disease During Pregnancy and Perinatal Outcomes: An Investigation of the Regulator in Japan. Med (Baltimore) (2015) 94(1):e386. doi: 10.1097/ MD.0000000000000386

30. Mayadas TN, Cullere X, Lowell CA. The Multifaceted Functions of Neutrophils. Annu Rev Pathol (2014) 9:181-218. doi: 10.1146/annurevpathol-020712-164023

31. Schauer C, Janko C, Munoz LE, Zhao Y, Kienhofer D, Frey B, et al. Aggregated Neutrophil Extracellular Traps Limit Inflammation by Degrading Cytokines and Chemokines. Nat Med (2014) 20(5):511-7. doi: $10.1038 / \mathrm{nm} .3547$

32. Fullerton JN, Gilroy DW. Resolution of Inflammation: A New Therapeutic Frontier. Nat Rev Drug Discov (2016) 15(8):551-67. doi: 10.1038/nrd. 2016.39

33. Kolaczkowska E, Kubes P. Neutrophil Recruitment and Function in Health and Inflammation. Nat Rev Immunol (2013) 13(3):159-75. doi: 10.1038/ nri3399

34. Choi JW, Im MW, Pai SH. Nitric Oxide Production Increases During Normal Pregnancy and Decreases in Preeclampsia. Ann Clin Lab Sci (2002) 32(3):257-63.

35. Liew PX, Kubes P. The Neutrophil's Role During Health and Disease. Physiol Rev (2019) 99(2):1223-48. doi: 10.1152/physrev.00012.2018

36. Aitken EH, Alemu A, Rogerson SJ. Neutrophils and Malaria. Front Immunol (2018) 9:3005. doi: 10.3389/fimmu.2018.03005

37. Amulic B, Moxon CA, Cunnington AJ. A More Granular View of Neutrophils in Malaria. Trends Parasitol (2020) 36(6):501-3. doi: 10.1016/ j.pt.2020.03.003

38. Sercundes MK, Ortolan LS, Debone D, Soeiro-Pereira PV, Gomes E, Aitken $\mathrm{EH}$, et al. Targeting Neutrophils to Prevent Malaria-Associated Acute Lung Injury/Acute Respiratory Distress Syndrome in Mice. PloS Pathogens (2016) 12(12):e1006054. doi: 10.1371/journal.ppat.1006054

39. Feintuch CM, Saidi A, Seydel K, Chen G, Goldman-Yassen A, MitaMendoza NK, et al. Activated Neutrophils Are Associated With Pediatric Cerebral Malaria Vasculopathy in Malawian Children. mBio (2016) 167(1): e01300-15. doi: 10.1128/mBio.01300-15

40. Porcherie A, Mathieu C, Peronet R, Schneider E, Claver J, Commere PH, et al. Critical Role of the Neutrophil-Associated High-Affinity Receptor for $\operatorname{IgE}$ in the Pathogenesis of Experimental Cerebral Malaria. J Exp Med (2011) 208(11):2225-36. doi: 10.1084/jem.20110845

41. Rocha BC, Marques PE, Leoratti FMS, Junqueira C, Pereira DB, Antonelli L, et al. Type I Interferon Transcriptional Signature in Neutrophils and LowDensity Granulocytes Are Associated With Tissue Damage in Malaria. Cell Rep (2015) 13(12):2829-41. doi: 10.1016/j.celrep.2015.11.055

42. Dasari P, Reiss K, Lingelbach K, Baumeister S, Lucius R, Udomsangpetch R, et al. Digestive Vacuoles of Plasmodium Falciparum Are Selectively Phagocytosed by and Impair Killing Function of Polymorphonuclear Leukocytes. Blood (2011) 118(18):4946-56. doi: 10.1182/blood-2011-05353920

43. Sarr D, Cooper CA, Bracken TC, Martinez-Uribe O, Nagy T, Moore JM. Oxidative Stress: A Potential Therapeutic Target in Placental Malaria. ImmunoHorizons (2017) 1(4):29-41. doi: 10.4049/immunohorizons.1700002

44. Megnekou R, Djontu JC, Bigoga JD, Medou FM, Tenou S, Lissom A. Impact of Placental Plasmodium Falciparum Malaria on the Profile of Some Oxidative Stress Biomarkers in Women Living in Yaounde, Cameroon PloS One (2015) 10(8):e0134633. doi: 10.1371/journal.pone.0134633

45. Sharma L, Kaur J, Shukla G. Role of Oxidative Stress and Apoptosis in the Placental Pathology of Plasmodium Berghei Infected Mice. PloS One (2012) 7(3):e32694. doi: 10.1371/journal.pone.0032694

46. Sharma L, Kaur J, Rishi P, Shukla G. Plasmodium Berghei: Influence of Infection on the Oxidant and Antioxidants Levels in Pregnant BALB/c Mice. Exp Parasitol (2012) 131(2):215-22. doi: 10.1016/j.exppara.2012.04.005

47. Brinkmann V, Zychlinsky A. Beneficial Suicide: Why Neutrophils Die to Make NETs. Nat Rev Microbiol (2007) 5(8):577-82. doi: 10.1038/ nrmicro 1710 
48. Brinkmann V, Reichard U, Goosmann C, Fauler B, Uhlemann Y, Weiss DS, et al. Neutrophil Extracellular Traps Kill Bacteria. Science (2004) 303 (5663):1532-5. doi: 10.1126/science.1092385

49. Masuda S, Nakazawa D, Shida H, Miyoshi A, Kusunoki Y, Tomaru U, et al. NETosis Markers: Quest for Specific, Objective, and Quantitative Markers. Clinica Chimica Acta; Int J Clin Chem (2016) 459:89-93. doi: 10.1016/ j.cca.2016.05.029

50. Kessenbrock K, Krumbholz M, Schonermarck U, Back W, Gross WL, Werb $Z$, et al. Netting Neutrophils in Autoimmune Small-Vessel Vasculitis. Nat Med (2009) 15(6):623-5. doi: 10.1038/nm.1959

51. Nakazawa D, Tomaru U, Suzuki A, Masuda S, Hasegawa R, Kobayashi T, et al. Abnormal Conformation and Impaired Degradation of PropylthiouracilInduced Neutrophil Extracellular Traps: Implications of Disordered Neutrophil Extracellular Traps in a Rat Model of Myeloperoxidase Antineutrophil Cytoplasmic Antibody-Associated Vasculitis. Arthritis Rheumatol (2012) 64(11):3779-87. doi: 10.1002/art.34619.Citedin:Pubmed

52. Gavillet M, Martinod K, Renella R, Harris C, Shapiro NI, Wagner DD, et al. Flow Cytometric Assay for Direct Quantification of Neutrophil Extracellular Traps in Blood Samples. Am J Hematol (2015) 90(12):1155-8. doi: 10.1002/ ajh. 24185

53. Tucker SL, Sarr D, Rada B. Neutrophil Extracellular Traps Are Present in the Airways of ENaC-Overexpressing Mice With Cystic Fibrosis-Like Lung Disease. BMC Immunol (2021) 22(1):7. doi: 10.1186/s12865-021-00397-w

54. Rodrigues DAS, Prestes EB, Gama AMS, Silva LS, Pinheiro AAS, Ribeiro JMC, et al. CXCR4 and MIF Are Required for Neutrophil Extracellular Trap Release Triggered by Plasmodium-Infected Erythrocytes. PloS Pathogens (2020) 16(8):e1008230. doi: 10.1371/journal.ppat.1008230

55. Chang Z, Jiang N, Zhang Y, Lu H, Yin J, Wahlgren M, et al. TatD-Like DNase of Plasmodium Is a Virulence Factor and a Potential Malaria Vaccine Candidate. Nat Commun (2016) 7:11537. doi: 10.1038/ ncomms 11537

56. Baker VS, Imade GE, Molta NB, Tawde P, Pam SD, Obadofin MO, et al. Cytokine-Associated Neutrophil Extracellular Traps and Antinuclear Antibodies in Plasmodium Falciparum Infected Children Under Six Years of Age. Malaria J (2008) 7:41. doi: 10.1186/1475-2875-7-41

57. Kho S, Minigo G, Andries B, Leonardo L, Prayoga P, Poespoprodjo JR, et al. Circulating Neutrophil Extracellular Traps and Neutrophil Activation Are Increased in Proportion to Disease Severity in Human Malaria. J Infect Dis (2019) 219(12):1994-2004. doi: 10.1093/infdis/jiy661

58. Knackstedt SL, Georgiadou A, Apel F, Abu-Abed U, Moxon CA, Cunnington AJ, et al. Neutrophil Extracellular Traps Drive Inflammatory Pathogenesis in Malaria. Sci Immunol (2019) 4(40):1-9. doi: 10.1126/ sciimmunol.aaw0336

59. Avery JW, Smith GM, Owino SO, Sarr D, Nagy T, Mwalimu S, et al. Maternal Malaria Induces a Procoagulant and Antifibrinolytic State That Is Embryotoxic But Responsive to Anticoagulant Therapy. PloS One (2012) 7 (2):e31090. doi: 10.1371/journal.pone.0031090

60. Othoro C, Moore JM, Wannemuehler K, Nahlen BL, Otieno J, Slutsker L, et al. Evaluation of Various Methods of Maternal Placental Blood Collection for Immunology Studies. Clin Vaccine Immunol (2006) 13(5):568-74. doi: 10.1128/CVI.13.5.568-574.2006

61. Ayisi JG, van Eijk AM, ter Kuile FO, Kolczak MS, Otieno JA, Misore AO, et al. The Effect of Dual Infection With HIV and Malaria on Pregnancy Outcome in Western Kenya. AIDS (2003) 17(4):585-94. doi: 10.1097/ 00002030-200303070-00014

62. Yoo DG, Winn M, Pang L, Moskowitz SM, Malech HL, Leto TL, et al. Release of Cystic Fibrosis Airway Inflammatory Markers From Pseudomonas Aeruginosa-Stimulated Human Neutrophils Involves NADPH Oxidase-Dependent Extracellular DNA Trap Formation. J Immunol (2014) 192(10):4728-38. doi: 10.4049/jimmunol.1301589

63. Floyd M, Winn M, Cullen C, Sil P, Chassaing B, Yoo DG, et al. Swimming Motility Mediates the Formation of Neutrophil Extracellular Traps Induced by Flagellated Pseudomonas Aeruginosa. PloS Pathogens (2016) 12(11): e1005987. doi: 10.1371/journal.ppat.1005987

64. Yadav R, Yoo DG, Kahlenberg JM, Bridges SL Jr, Oni O, Huang H, et al. Systemic Levels of Anti-PAD4 Autoantibodies Correlate With Airway Obstruction in Cystic Fibrosis. J Cyst Fibros (2019) 18(5):636-45. doi: 10.1016/j.jcf.2018.12.010
65. Yadav R, Linnemann RW, Kahlenberg JM, Bridges LS Jr, Stecenko AA, Rada B. IgA Autoantibodies Directed Against Self DNA Are Elevated in Cystic Fibrosis and Associated With More Severe Lung Dysfunction. Autoimmunity (2020) 53(8):476-84. doi: 10.1080/08916934.2020.1839890

66. Sarr D, Bracken TC, Owino SO, Cooper CA, Smith GM, Nagy T, et al. Differential Roles of Inflammation and Apoptosis in Initiation of MidGestational Abortion in Malaria-Infected C57BL/6 and a/J Mice. Placenta (2015) 36(7):738-49. doi: 10.1016/j.placenta.2015.04.007

67. Bankhead P, Loughrey MB, Fernandez JA, Dombrowski Y, McArt DG, Dunne PD, et al. QuPath: Open Source Software for Digital Pathology Image Analysis. Sci Rep (2017) 7(1):16878. doi: 10.1038/s41598-017-17204-5

68. Ginley BG, Emmons T, Lutnick B, Urban CF, Segal BH, Sarder P. Computational Detection and Quantification of Human and Mouse Neutrophil Extracellular Traps in Flow Cytometry and Confocal Microscopy. Sci Rep (2017) 7(1):17755. doi: 10.1038/s41598-017-18099-y

69. Menendez C, Ordi J, Ismail MR, Ventura PJ, Aponte JJ, Kahigwa E, et al. The Impact of Placental Malaria on Gestational Age and Birth Weight. J Infect Dis (2000) 181(5):1740-5. doi: 10.1086/315449

70. Bulmer JN, Rasheed FN, Francis N, Morrison L, Greenwood BM. Placental Malaria. I. Pathological classification. Histopathology (1993) 22(3):211-8. doi: 10.1111/j.1365-2559.1993.tb00110.x

71. Ismail MR, Ordi J, Menendez C, Ventura PJ, Aponte JJ, Kahigwa E, et al. Placental Pathology in Malaria: A Histological, Immunohistochemical, and Quantitative Study. Hum Pathol (2000) 31(1):85-93. doi: 10.1016/S0046-8177(00)80203-8

72. Rogerson SJ, Hviid L, Duffy PE, Leke RF, Taylor DW. Malaria in Pregnancy: Pathogenesis and Immunity. Lancet Infect Dis (2007) 7(2):105-17. doi: 10.1016/S1473-3099(07)70022-1

73. Muehlenbachs A, Fried M, McGready R, Harrington WE, Mutabingwa TK, Nosten F, et al. A Novel Histological Grading Scheme for Placental Malaria Applied in Areas of High and Low Malaria Transmission. J Infect Dis (2010) 202(10):1608-16. doi: 10.1086/656723

74. Urban CF, Ermert D, Schmid M, Abu-Abed U, Goosmann C, Nacken W, et al. Neutrophil Extracellular Traps Contain Calprotectin, a Cytosolic Protein Complex Involved in Host Defense Against Candida Albicans. PloS Pathogens (2009) 5(10):e1000639. doi: 10.1371/journal.ppat.1000639

75. Papayannopoulos V, Metzler KD, Hakkim A, Zychlinsky A. Neutrophil Elastase and Myeloperoxidase Regulate the Formation of Neutrophil Extracellular Traps. J Cell Biol (2010) 191(3):677-91. doi: 10.1083/jcb.201006052

76. Sarr D, Marrama L, Gaye A, Dangou JM, Niang M, Mercereau-Puijalon O, et al. High Prevalence of Placental Malaria and Low Birth Weight in Sahelian Periurban Area. Am J Trop Med Hygiene (2006) 75(1):171-7. doi: 10.4269/ajtmh.2006.75.171

77. Davison BB, Kaack MB, Rogers LB, Rasmussen KK, Rasmussen T, Henson EW, et al. Alterations in the Profile of Blood Cell Types During Malaria in Previously Unexposed Primigravid Monkeys. J Infect Dis (2005) 191 (11):1940-52. doi: 10.1086/430004

78. Mandala WL, Gondwe EN, Molyneux ME, MacLennan JM, MacLennan CA. Leukocyte Counts and Lymphocyte Subsets in Relation to Pregnancy and HIV Infection in Malawian Women. Am J Reprod Immunol (2017) 78(3):1-7. doi: $10.1111 /$ aji.12678

79. Giaglis S, Stoikou M, Grimolizzi F, Subramanian BY, van Breda SV, Hoesli I, et al. Neutrophil Migration Into the Placenta: Good, Bad or Deadly? Cell Adh Migr (2016) 10(1-2):208-25. doi: 10.1080/19336918.2016.1148866

80. Knall C, Worthen GS, Johnson GL. Interleukin 8-Stimulated Phosphatidylinositol-3-Kinase Activity Regulates the Migration of Human Neutrophils Independent of Extracellular Signal-Regulated Kinase and P38 Mitogen-Activated Protein Kinases. Proc Natl Acad Sci USA (1997) 94 (7):3052-7. doi: 10.1073/pnas.94.7.3052

81. Lucchi NW, Sarr D, Owino SO, Mwalimu SM, Peterson DS, Moore JM. Natural Hemozoin Stimulates Syncytiotrophoblast to Secrete Chemokines and Recruit Peripheral Blood Mononuclear Cells. Placenta (2011) 32 (8):579-85. doi: 10.1016/j.placenta.2011.05.003

82. Vasquez AM, Segura C, Blair S. Induction of Pro-Inflammatory Response of the Placental Trophoblast by Plasmodium Falciparum Infected Erythrocytes and TNF. Malaria J (2013) 12:421. doi: 10.1186/1475-2875-12-421

83. Stockfelt M, Larsson G, Engstrom H, Puttonen H, Zetterberg H, Blennow K, et al. Activated Low-Density Granulocytes in Peripheral and Intervillous Blood and Neutrophil Inflammation in Placentas From SLE Pregnancies. Lupus Sci Med (2021) 8(1):1-12. doi: 10.1136/lupus-2020-000463 
84. Pullar JM, Vissers MC, Winterbourn CC. Living With a Killer: The Effects of Hypochlorous Acid on Mammalian Cells. IUBMB Life (2000) 50(4-5):25966. doi: $10.1080 / 713803731$

85. Theess W, Sellau J, Steeg C, Klinke A, Baldus S, Cramer JP, et al. Myeloperoxidase Attenuates Pathogen Clearance During Plasmodium Yoelii Nonlethal Infection. Infect Immun (2017) 85(1):1-10. doi: 10.1128/IAI.00475-16

86. Vita JA, Brennan ML, Gokce N, Mann SA, Goormastic M, Shishehbor MH, et al. Serum Myeloperoxidase Levels Independently Predict Endothelial Dysfunction in Humans. Circulation (2004) 110(9):1134-9. doi: 10.1161/ 01.CIR.0000140262.20831.8F

87. Sugiyama S, Okada Y, Sukhova GK, Virmani R, Heinecke JW, Libby P. Macrophage Myeloperoxidase Regulation by Granulocyte Macrophage Colony-Stimulating Factor in Human Atherosclerosis and Implications in Acute Coronary Syndromes. Am J Pathol (2001) 158(3):879-91. doi: 10.1016/S0002-9440(10)64036-9

88. Klebanoff SJ. Myeloperoxidase: Friend and Foe. J Leukoc Biol (2005) 77 (5):598-625. doi: 10.1189/jlb.1204697

89. Gandley RE, Rohland J, Zhou Y, Shibata E, Harger GF, Rajakumar A, et al. Increased Myeloperoxidase in the Placenta and Circulation of Women With Preeclampsia. Hypertension (2008) 52(2):387-93. doi: 10.1161/ HYPERTENSIONAHA.107.107532

90. Hung TH, Chen SF, Lo LM, Li MJ, Yeh YL, Hsieh TT. Myeloperoxidase in the Plasma and Placenta of Normal Pregnant Women and Women With Pregnancies Complicated by Preeclampsia and Intrauterine Growth Restriction. Placenta (2012) 33(4):294-303. doi: 10.1016/j.placenta.2012.01.004

91. Mruma HA, McQuillan R, Norrie J. The Association of Malaria Infection and Gestational Hypertension in Africa: Systematic Review and MetaAnalysis. J Glob Health (2020) 10(2):20417. doi: 10.7189/jogh.10.020417

92. Obiri D, Erskine IJ, Oduro D, Kusi KA, Amponsah J, Gyan BA, et al. Histopathological Lesions and Exposure to Plasmodium Falciparum Infections in the Placenta Increases the Risk of Preeclampsia Among Pregnant Women. Sci Rep (2020) 10(1):8280. doi: 10.1038/s41598-020-64736-4

93. Prato M, Giribaldi G, Polimeni M, Gallo V, Arese P. Phagocytosis of Hemozoin Enhances Matrix Metalloproteinase-9 Activity and TNF-Alpha Production in Human Monocytes: Role of Matrix Metalloproteinases in the Pathogenesis of Falciparum Malaria. J Immunol (2005) 175(10):6436-42 doi: 10.4049/jimmunol.175.10.6436

94. Prato M, Gallo V, Giribaldi G, Arese P. Phagocytosis of Haemozoin (Malarial Pigment) Enhances Metalloproteinase-9 Activity in Human Adherent Monocytes: Role of IL-1beta and 15-HETE. Malaria J (2008) 7:157. doi: 10.1186/1475-2875-7-157

95. Prato M, Giribaldi G. Matrix Metalloproteinase- 9 and Haemozoin: Wedding Rings for Human Host and Plasmodium Falciparum Parasite in Complicated Malaria. J Trop Med (2011) 2011:628435. doi: 10.1155/2011/628435

96. Apoorv TS, Babu PP, Meese S, Gai PP, Bedu-Addo G, Mockenhaupt FP. Matrix Metalloproteinase-9 Polymorphism 1562 C > T (Rs3918242) Associated With Protection Against Placental Malaria. Am J Trop Med Hygiene (2015) 93(1):186-8. doi: 10.4269/ajtmh.14-0816

97. Porto BN, Stein RT. Neutrophil Extracellular Traps in Pulmonary Diseases: Too Much of a Good Thing? Front Immunol (2016) 7:311. doi: 10.3389/ fimmu.2016.00311

98. Rada B. Neutrophil Extracellular Traps. Methods Mol Biol (2019) 1982:51728. doi: 10.1007/978-1-4939-9424-3_31
99. Rada B. Interactions Between Neutrophils and Pseudomonas Aeruginosa in Cystic Fibrosis. Pathogens (2017) 6(1):1-24. doi: 10.3390/pathogens6010010

100. Tsukimori K, Nakano H, Wake N. Difference in Neutrophil Superoxide Generation During Pregnancy Between Preeclampsia and Essential Hypertension. Hypertension (2007) 49(6):1436-41. doi: 10.1161/ HYPERTENSIONAHA.106.086751

101. Agarwal A, Aponte-Mellado A, Premkumar BJ, Shaman A, Gupta S. The Effects of Oxidative Stress on Female Reproduction: A Review. Reprod Biol Endocrinol (2012) 10:49. doi: 10.1186/1477-7827-10-49

102. Aly AS, Khandelwal M, Zhao J, Mehmet AH, Sammel MD, Parry S. Neutrophils Are Stimulated by Syncytiotrophoblast Microvillous Membranes to Generate Superoxide Radicals in Women With Preeclampsia. Am J Obstetrics Gynecol (2004) 190(1):252-8. doi: 10.1016/j.ajog.2003.07.003

103. Gupta AK, Hasler P, Holzgreve W, Hahn S. Neutrophil NETs: A Novel Contributor to Preeclampsia-Associated Placental Hypoxia? Semin Immunopathol (2007) 29(2):163-7. doi: 10.1007/s00281-007-0073-4

104. Hahn S, Giaglis S, Hoesli I, Hasler P. Neutrophil NETs in Reproduction: From Infertility to Preeclampsia and the Possibility of Fetal Loss. Front Immunol (2012) 3:362. doi: 10.3389/fimmu.2012.00362

105. Marder W, Knight JS, Kaplan MJ, Somers EC, Zhang X, O’Dell AA, et al. Placental Histology and Neutrophil Extracellular Traps in Lupus and PreEclampsia Pregnancies. Lupus Sci Med (2016) 3(1):e000134. doi: 10.1136/ lupus-2015-000134

106. Pattison DI, Davies MJ, Hawkins CL. Reactions and Reactivity of Myeloperoxidase-Derived Oxidants: Differential Biological Effects of Hypochlorous and Hypothiocyanous Acids. Free Radic Res (2012) 46 (8):975-95. doi: 10.3109/10715762.2012.667566

107. Rayner BS, Love DT, Hawkins CL. Comparative Reactivity of Myeloperoxidase-Derived Oxidants With Mammalian Cells. Free Radical Biol Med (2014) 71:240-55. doi: 10.1016/j.freeradbiomed.2014.03.004

108. Winterbourn CC, Kettle AJ. Redox Reactions and Microbial Killing in the Neutrophil Phagosome. Antioxid Redox Signal (2013) 18(6):642-60. doi: 10.1089 /ars.2012.4827

Conflict of Interest: LA was employed by \#1 Heartsaved Adult Family Care.

The remaining authors declare that the research was conducted in the absence of any commercial or financial relationships that could be construed as a potential conflict of interest.

Publisher's Note: All claims expressed in this article are solely those of the authors and do not necessarily represent those of their affiliated organizations, or those of the publisher, the editors and the reviewers. Any product that may be evaluated in this article, or claim that may be made by its manufacturer, is not guaranteed or endorsed by the publisher.

Copyright (c) 2021 Sarr, Oliveira, Russ, Owino, Middii, Mwalimu, Ambasa, Almutairi, Vulule, Rada and Moore. This is an open-access article distributed under the terms of the Creative Commons Attribution License (CC BY). The use, distribution or reproduction in other forums is permitted, provided the original author(s) and the copyright owner(s) are credited and that the original publication in this journal is cited, in accordance with accepted academic practice. No use, distribution or reproduction is permitted which does not comply with these terms. 